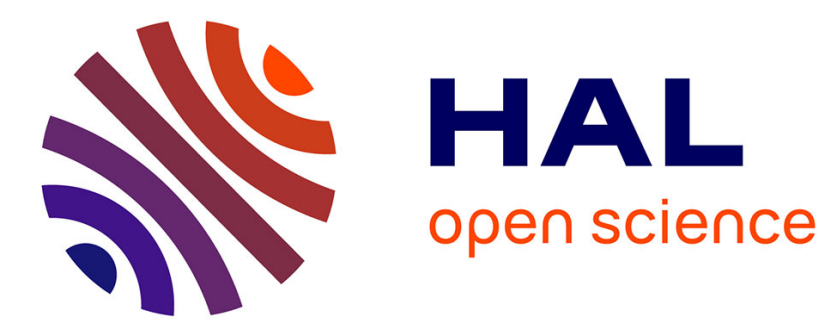

\title{
Porphyrin and phthalocyanine-based metal organic frameworks beyond metal-carboxylates
}

\author{
Siddhartha De, Thomas Devic, Alexandra Fateeva
}

\section{To cite this version:}

Siddhartha De, Thomas Devic, Alexandra Fateeva. Porphyrin and phthalocyanine-based metal organic frameworks beyond metal-carboxylates. Dalton Transactions, 2021, 50 (4), pp.1166-1188. 10.1039/D0DT03903A . hal-03132936

\section{HAL Id: hal-03132936 \\ https://hal.science/hal-03132936}

Submitted on 21 Apr 2021

HAL is a multi-disciplinary open access archive for the deposit and dissemination of scientific research documents, whether they are published or not. The documents may come from teaching and research institutions in France or abroad, or from public or private research centers.
L'archive ouverte pluridisciplinaire HAL, est destinée au dépôt et à la diffusion de documents scientifiques de niveau recherche, publiés ou non, émanant des établissements d'enseignement et de recherche français ou étrangers, des laboratoires publics ou privés. 


\title{
Porphyrin and phthalocyanine-based Metal Organic Frameworks beyond metal-carboxylates
}

\author{
Siddhartha De, ${ }^{a}$ Thomas Devic ${ }^{b}$ and Alexandra Fateeva ${ }^{a^{*}}$
}

\author{
a Univ. Lyon, Université Claude Bernard Lyon 1, Laboratoire des Multimatériaux et Interfaces, UMR CNRS \\ 5615, F-69622 Villeurbanne, France. \\ E-mail: alexandra.fateeva@univ-lyon1.fr \\ ${ }^{b}$ Université de Nantes, CNRS, Institut des Matériaux Jean Rouxel, IMN, F-44000 Nantes, France
}

\begin{abstract}
Given the ubiquitous role of porphyrins in natural systems, these molecules and related derivatives such as phthalocyanines are fascinating building units to achieve functional porous materials. Porphyrin-based MOFs have been developed since the past three decades, yet chemically robust frameworks, necessary for applications, have been achieved much more recently and this field is expanding. This progress is partially driven by the development of porphyrins and phthalocyanines bearing alternative coordinating groups (phosphonate, azolates, phenolates...) that allowed to move the related MOFs beyond metalcarboxylates and achieve new topologies and properties. In this perspective article we first give a brief outline of the synthetic pathways towards simple porphyrins and phthalocyanines bearing these complexing groups. The related MOF compounds are then described; their structural and textural properties are discussed, as well as their stability and physical properties. An overview of the resulting nets and topologies is proposed, showing both the similarities with metal-carboxylate phases and the peculiarities related to the alternative coordinating groups. Eventually, the opportunities offered by this recent research topic, both in term of synthesis pathways, modulation of pore size and shape, stability and physical properties, are discussed
\end{abstract}

\section{Introduction}

Metalloporphyrins and related molecules (chlorins, corrins...) represent a class of coordination compounds widely involved in essential natural processes such as light harvesting, electron and oxygen transfer. These molecules are naturally found in microbial systems, plants, animals and humans where they are active centres for key transformations such as photosynthesis, breathing, bioremediation and detoxification ${ }^{1}$. They became widely accessible to synthetic chemists starting from 1960's, and substantial effort in organic synthesis was provided in the following decades to optimise the access to purposely designed functionalised macrocycles. By these means, synthetic models for complex natural systems were developed, and allowed some understanding of the essential biochemical reactions. Sophisticated supramolecular assemblies were characterised and studied for numerous applications related to the properties of porphyrins, such as redox catalysis, binding of small molecules, and light harvesting. Phthalocyanines, at the other hand are not involved in natural systems, they have been discovered accidentally during an industrial chemical process. Since the 1930's, they are widely manufactured mainly to be used as blue and green pigments and dyes. Similarities between both kinds of macrocycles promoted research studies of their properties in similar domains. Both class of molecules are aromatic (18 conjugated $\pi$-electrons), this conjugation provides very high molar extinction coefficients along with good chemical and thermal stability, and functionalised derivatives are now easily available. From here, it does not appear surprising that materials chemists used metalloporphyrins and metallophthalocyanines as building units for assembling coordination and covalent frameworks. Indeed, building porous and crystalline frameworks based on such molecules is an appealing and elegant way to structure them in solid state and in an organised manner with a potentially high concentration of accessible active sites. This is one way to better understand and study the structure-properties relationships on a fundamental level, and to aim molecular materials with designed properties for applications in sensing ${ }^{2-4}$, solar cells sensitizers $^{5-7}$, photocatalysis $^{8-11}$, detoxification ${ }^{12-15}$, redox catalysis ${ }^{16-20}$, energy storage ${ }^{21,22}$, electrode materials ${ }^{23,24}$, and photodynamic therapy ${ }^{25-30}$. 
In terms of porphyrin-based MOFs, first examples were described as early as 1990's31,32, but the development of permanently porous and chemically robust materials was mainly achieved only from the last decade. This promoted an in-depth exploration of the intriguing potentials of these functional materials. Regarding phthalocyanine-based MOFs, fewer examples are available in the literature but noticeable progress is being made very recently. Of course, development of porphyrins and phthalocyanines-based MOFs follow trends and interests of general MOF chemistry and depend also on the ease of synthesis of the desired ligands (discussed in the section below). This is why carboxylate and pyridine functionalised porphyrins are the most widely used linkers, that recently became commercially available in a multi-gram scale. Note that the synthesis and commercial availability of functionalised phthalocyanine ligands is more limited for now. Few review articles described the state of the art of porphyrinbased MOFs in the past years,33-36 where the great majority of examples concerned the above-mentioned carboxylate and pyridyl functionalities. In this review, we wish to highlight the development of porphyrin and phthalocyanine MOFs based on non-carboxylate anionic linkers potentially featuring original and for now less developed architectures, as well as new properties. This review focuses on MOFs where porphyrins or phthalocyanines act as building units and do not include examples of MOFs encapsulating these macrocycles. More importantly, we would like to make a distinction between MOFs and supramolecular assemblies (out of the scope of this review), that in our opinion are sometimes erroneously named MOFs in the literature. An easy way to clarify this point can be to consider that open framework structures are built from two distinct organic and inorganic building units, therefore, an assembly based on the coordination of metalloporphyrins or metallophthalocyanines through axial ligation (based on only one building unit) should not be included in the class of MOFs in our sense.

This article is organised in three main sections; firstly, the ligands synthetic approaches are detailed to give to the readers an overview and tools for some porphyrins and phthalocyanines design and synthesis strategies. Secondly, a comprehensive review of corresponding MOFs is provided with an outlook on the synthesis conditions, topology,

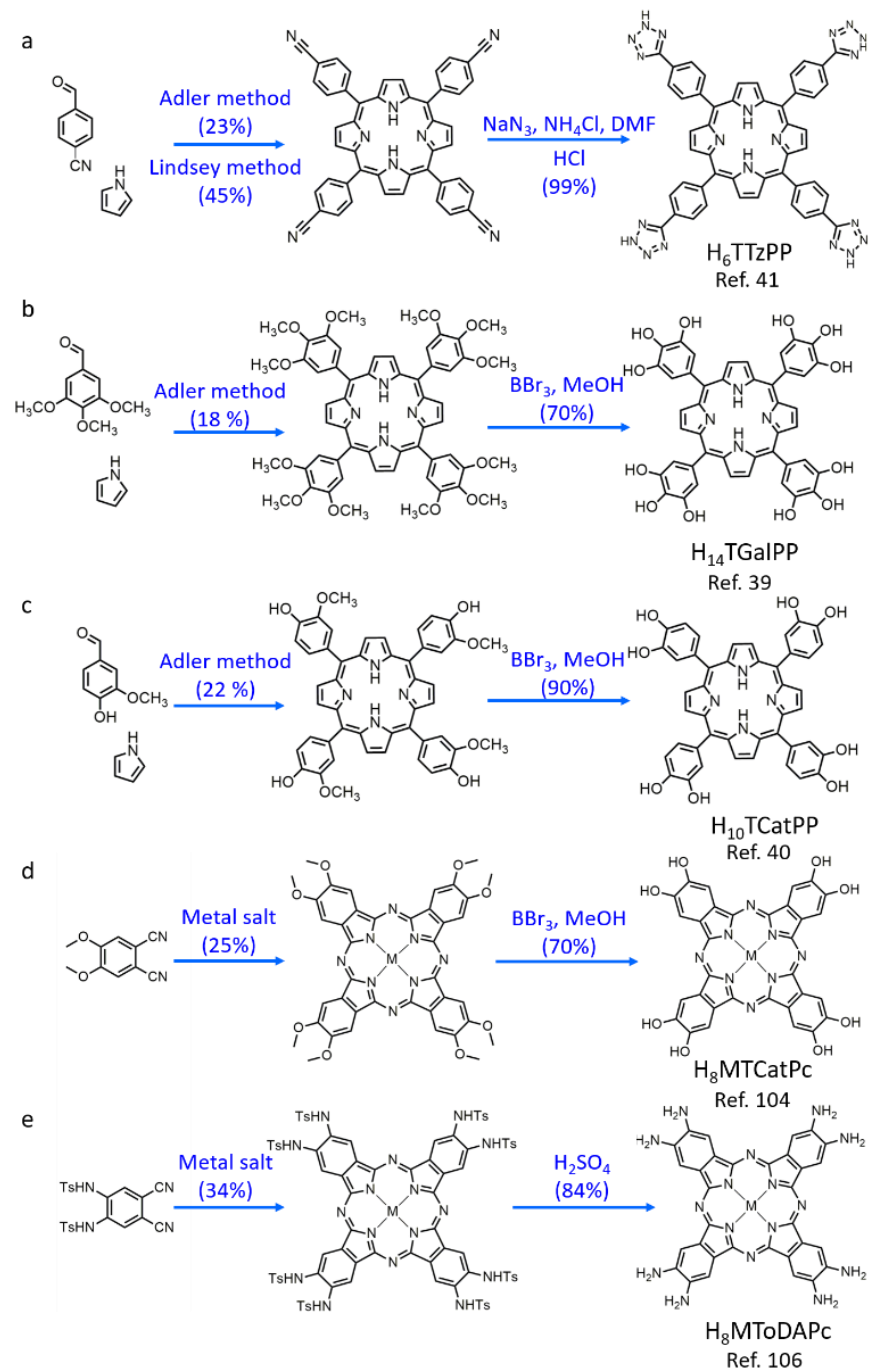

Scheme 1: two-steps synthesis pathways for porphyrins and phthalocyanines. 


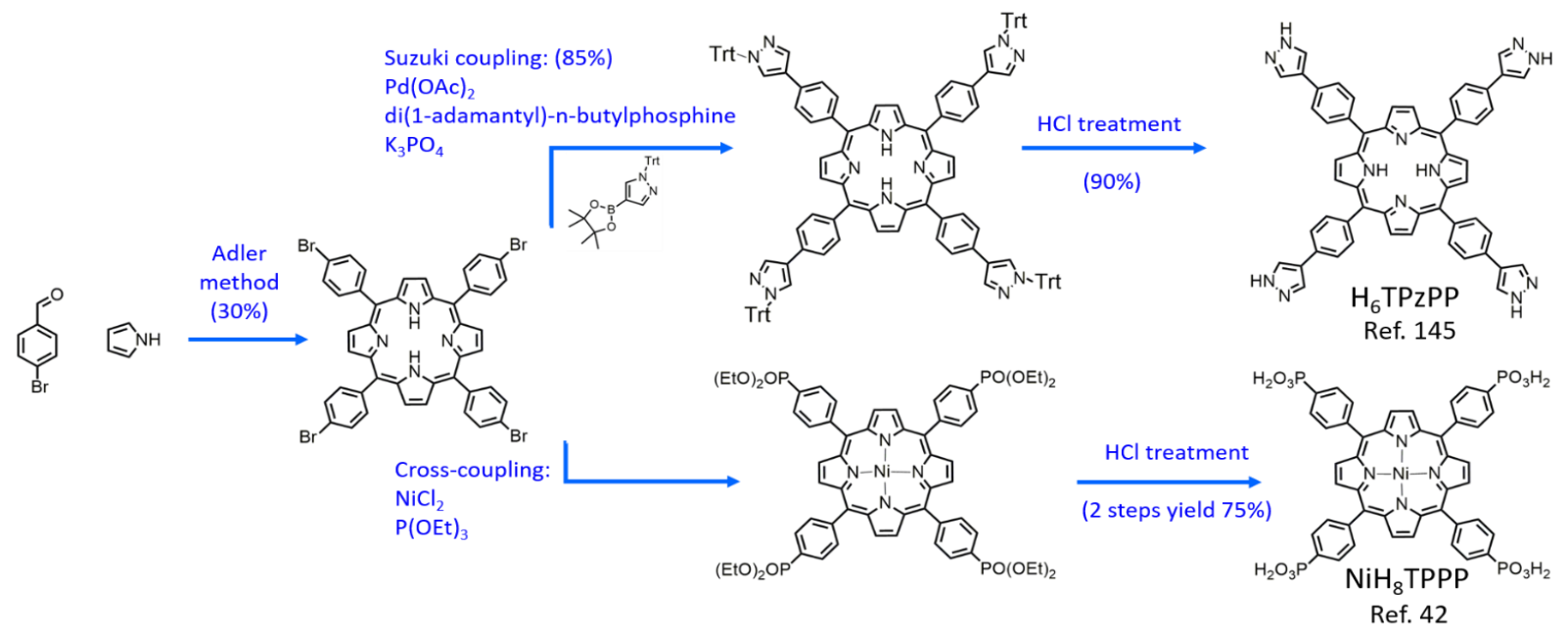

Scheme 2: three-steps synthesis pathways for porphyrins through cross-coupling reactions.

stability and functionality of these materials. In the last section we drive a summary and trends as an overview of these materials.

\section{Synthesis of porphyrins and phthalocyanines ligands}

The synthesis science of porphyrins and phthalocyanines is an extremely wide topic, and this article only aims to pragmatically describe the synthetic pathways for molecules that are used for building MOFs. These molecules are accessible in most of the synthetic chemistry labs, and even though their synthesis is reputed to be tricky, now convenient methods are developed to reach gram-scale quantities. In the scope of our review, we only discuss here tetra-substituted aryl-porphyrins and symmetric phthalocyanines.

\section{Porphyrinic ligands}

Porphyrins bearing four identical aromatic substituents at the meso-positions (A-4 porphyrins) are usually the easiest ones to synthesize in a scale well-suited for exploring MOF assemblies. Commercial access to some of A-4 porphyrins has improved in the recent years, in terms of purity and prices, this is valid for the tetrakis(4carboxyphenyl)porphyrin (TCPP) and tetrakis (4-sulfonatophenyl)porphyrin (TSPP) molecules and contributes to the fact that several examples of MOFs are reported based on these two linkers. Still, to access original topologies and designed properties, tailor-made A-4 porphyrins can be synthesised in any chemistry lab, therefore commercial availability does not have to limit the choice of porphyrinic linkers.

In terms of A-4 porphyrins synthesis, two main strategies are widely followed: the Adler-Longo ${ }^{37}$ and the Lindsey ${ }^{38}$ methods. Either way, these porphyrins are obtained by acid-catalysed condensation of four pyrroles and aldehydes, giving a porphyrinogen which is then oxidized to a porphyrin. Historically, Adler's method was the first one to give decent yields for the synthesis of a variety of substituted porphyrins. In this approach, substituted benzaldehyde and pyrrole are refluxed in propionic acid ( $\sim 0.5 \mathrm{M}$ solution) under air which allows the in-situ oxidation of the porphyrinogen and leads directly to the porphyrin product. In best cases, the desired product crystallises in the reaction mixture and is recovered by filtration. This method allows $\sim 20 \%$ yields for many para-substituted benzaldehydes that are stable under the above synthesis conditions and remains very popular. The need to widen the scope of accessible molecules encouraged the development of milder synthetic pathway by Lindsey's group in the 1980's. This approach is based on an ambient or moderate temperature, two steps one flask strategy. First the condensation reaction is performed under acid catalysis (trifluoroacetic acid, $\mathrm{TFA}_{\mathrm{A}} \mathrm{or}_{3} \mathrm{BF}_{3} \mathrm{Et}$ ) in chlorinated solvent, followed by an oxidation step (2,3-dichloro-5,6-dicyano-1,4-benzoquinone, DDQ or $p$-chloranil oxidants). When the starting aldehyde presents electron-withdrawing substituents, Lindsey's method is usually preferable, for example, it is often the best strategy for the synthesis of perfluorinated porphyrins. Generally, this method can lead to higher yields (up to $50 \%$ ) but requires to work with very diluted conditions ( $\left.10^{-2} \mathrm{M}\right)$. Therefore, where applicable, Adler's approach is preferred as it avoids use of large amounts of solvents and often allows an easy product recovery through crystallization/filtration.

Most of the ligands of interest for this review can be synthesised in 2 steps (Scheme 1 ). In case of porphyrins, the general pathway involves the formation of an intermediate porphyrin followed by its functionalisation and/or deprotection of the coordinating function. Usually the intermediate porphyrin formation is the yield-limiting step 
and the functionalisation/deprotection is commonly achieved with high yields. Note that in most of the procedures, a metal-free porphyrin is obtained, however attention is needed when metal-catalysed coupling reactions are used, as metal catalyst can get chelated by the macrocycle. Also, in some cases the porphyrin can be obtained as a doubly protonated salt, due to the acidic treatment at the last synthesis step. It can then be either neutralised or used directly in its protonated form.

The sulfonatophenyl porphyrin (TSPP) synthesis is not represented here as it is a commercially accessible, inexpensive compound. Alternatively, it can be easily synthesized from tetraphenyl porphyrin (TPP) and concentrated sulfuric acid. Both poly-phenolic porphyrins are achieved through similar reaction pathway: first the formation of the methoxy-derivative, followed by the demethylation by $\mathrm{BBr}_{3}$ that can be used either in its diluted (less hazardous) form to reach catechol function, or as neat (be careful of pyrophoric hazard) to reach pyrogallol ${ }^{39,40}$. For tetrazole-functionalised porphyrin, first the intermediate porphyrin is formed from 4-formylbenzonitrile and pyrrole. This molecule then undergoes classical 1,3-dipolar cycloaddition of sodium azide (careful of explosive hazards) to the nitrile triple bond ${ }^{41}$. In case of pyrazole and phosphonate functionalisation, 3 steps are needed (Scheme 2). The first intermediate for both cases is the tetrabromophenyl-porphyrin. This halogenated compound is interesting as it can undergo a number of coupling reactions. Here, the pyrazolyl function can be introduced through Suzuki coupling of a protected pyrazole-boroester, followed by an easy deprotection in diluted acidic solution. To synthesise phosphonatophenyl compound, the highest yield was reported by performing the phosphorylation reaction in presence of 3.7 equivalents of $\mathrm{NiCl}_{2}$ catalyst, followed by hydrolysis of the octaethylester in concentrated $\mathrm{HCl}$ solution ${ }^{42}$. In this case, $\mathrm{Ni}^{2+}$ metallates the porphyrinic macrocycle, and remains there after concentrated acid treatment. Metal-free product is accessible if the phosphorylation is performed in presence of catalytic amount of $\mathrm{Pd}\left(\mathrm{PPh}_{3}\right)_{4}$, but in this case the reported final yield is much lower ${ }^{43}$.

\section{Phthalocyanine ligands}

Many synthetic methods are reported for phthalocyanines preparation, depending on the substituents on the benzene ring and whether a metallated phthalocyanine (MPc) or a free base is desired. Classically, a templated synthesis strategy is widely used, to reach a MPc. In this case, substituted phthalodinitrile or a derivative precursor is reacted at high temperature (high boiling point solvent or even neat reactants) in the presence of metal ions and a base. The MPc is formed through tetracyclization of the precursor and precipitates in the reaction flask. Phthalocyanines are known to chelate most of metals, but with divalent ions a stable and neutral complex is obtained, as described in the examples below. In comparison with porphyrins, phthalocyanines are planar molecules that are much less soluble. This low solubility issue leads to intricate purification and spectroscopic characterisations.

This last issue certainly contributes to the fact that for now, much less diversity in terms of coordination functions can be found in phthalocyanine based MOFs. Note that two positions on the phenyl ring have to be substituted to give rise to a symmetrical molecule and avoid isomeric mixtures. Indeed, most of them are based on the catechol function and one example is based on the diamino chelating function. All these molecules are symmetrical phthalocyanines that are synthesized in their metallated form. The synthesis proceeds through 2 main steps (Scheme $1 \mathrm{~d}$ and e): first the metaltemplated cyclo-tetramerisation of the phthalonitrile in a high boiling point solvent in presence of a base leads to an intermediate metallophthalocyanine. This molecule is then deprotected in the second step. Yields of functionalised phthalonitrile cyclisation are usually moderate (Scheme $1 \mathrm{~d}$ and e) and somehow comparable to the porphyrins formation yields, however, rather high concentrations $(\sim 0.5 \mathrm{M})$ can be used that allow the recovery of the product on a gram scale. For the catechol functionalised molecule, the synthesis strategy is similar to the porphyrinic counterpart. The octamethoxy metallophthalocyanine is obtained from the 4,5-dimethoxyphthalonitrile. This synthesis can be achieved in presence of different metallic ions such as $\mathrm{Co}^{2+}, \mathrm{Zn}^{2+}, \mathrm{Ni}^{2+}, \mathrm{Cu}^{2+}$ by slightly altering the conditions (solvent, nature of the base). Then, the classical $\mathrm{BBr}_{3}$ demethylation reaction gives the desired metalloligand. In case of the diamino compound, the $\mathrm{NH}_{2}$ groups have to be protected prior to the cyclisation step, which is done with Tosyl (Ts) protecting group. These groups are then cleaved by acidic treatment.

Aforementioned solubility issues persist when MPcs are used for MOF synthesis, leading to the precipitation of low crystalline materials. In fact, only one MOF was synthesised in single crystalline form for now ${ }^{19}$. If the related MOF chemistry remains less developed, phthalocyanines present interesting and complementary properties when compared to porphyrins. Indeed, they display strong absorption at higher wavelengths (red region), that are of interest for biomedical applications, higher thermal stability and higher charge carrier mobility that are promising for catalysts and devices development.

It seems important to highlight here the issue of metal insertion. Given that the macrocycle core is a very good complexing site, competition between coordinating functions (the core and the peripheral groups) can arise during the MOF synthesis, this is especially the case for divalent metals. For this reason, one strategy is to proceed to the macrocycle metalation prior to the deprotection of the coordination functions to avoid this competition. It is then important to check for potential metal exchange during the MOF synthesis. Another possibility to obtain a desired MOF composition is to work with free base 
compounds and proceed to the metal insertion through post-synthesis modification (PSM) of the MOF, this is possible when the MOF is based on a metal that is not easily chelated by the macrocycle (such as $\mathrm{Al}(\mathrm{III})$ or $\mathrm{Zr}$ (IV) ions for example).

\section{Metal Organic Frameworks based on porphyrins and phthalocyanines ligands}

\section{Oxygen donor ligands}

\section{Sulfonates}

Sulfonate based MOFs are relatively little investigated in the literature, mainly, because of the fairly weak ligation of metallic cations by sulfonates, when compared to the carboxylates. Sulfonic acids usually display low (often negative) pKa and therefore, sulfonates are lower Lewis bases compared to carboxylates. In presence of water, formation of ion-pairs (hydrated metallic cation with the sulfonate anion) rather than coordination assemblies can be observed for hard Lewis acids ${ }^{44}$ such as $\mathrm{Fe}(\mathrm{III})^{45}$ or $\mathrm{Al}(\mathrm{III})^{46}$. When proper coordination is achieved, the polarity of the sulfonate function may lead to strong interactions with guests inside the pores. This explains that truly stable and permanently porous metal sulfonate networks remain scarce. Moreover, the design and predictability of network structures is hindered by the versatility of potential coordination modes of sulfonate groups. However, the drawbacks of sulfonate-based MOFs also offer potential benefits, such as enabling flexibility and phase transitions, also strong interaction with polar species can lead to enhanced affinity for specific adsorbates ${ }^{47}$ and ionic conduction $^{48}$.

In terms of porphyrin and phthalocyanine chemistry, ionizable sulfonate functionalization is appealing for the design of water-soluble molecules in a wide $\mathrm{pH}$-range (from $\mathrm{pH} 3$ to basic $\mathrm{pH}$ ) and therefore, is useful for biological and medical research.

Only porphyrin-based metal sulfonate frameworks made of TSPP are reported in the literature for now. Tetrasulfonate-functionalized phthalocyanines have been also used for the synthesis of hybrid materials such as intercalation compounds with layered double hydroxides ${ }^{49,50}$ or nanoparticule-assemblies ${ }^{51}$ but no crystalline MOFs are reported. Regarding the synthesis conditions, sulfonate porphyrin-based MOFs are usually obtained in aqueous medium and at rather high temperatures $\left(150\right.$ to $\left.200{ }^{\circ} \mathrm{C}\right)$. Noticeably, the $\mathrm{pH}$ can have a major impact on the synthesis outcome ${ }^{52}$, as discussed hereunder. MOFs structures diversity remains quite limited; mostly lanthanide- 
based materials have been reported. A series of isotopic Ln-based MOFs were reported by Chen et al. ${ }^{53-55,55-64}$ these 3-D structures are based on rod-like inorganic secondary building units (SBU) where the Ln ions are bridged by eight sulfonates from eight different porphyrins. All the sulfonates display the same $\eta^{2}, \mu^{2}$ bidentate binuclear coordination mode: they are coordinated by two $\mathrm{O}$ atoms in a bridging mode and leave the third pending oxygen free (Figure 1a). Thus, the inorganic chain is built up from distorted square antiprisms bridged by the sulfonates. Given the similar chemical and geometrical properties of $\operatorname{Ln}(\mathrm{III})$ cations, this topology was described for a range of lanthanides with the free base porphyrin, and a few were studied with vanadium, zinc and cobalt metalloporphyrins. In these structures, the porphyrins are stacked with an inter-core distance of ca. $4.9 \AA$ but not perfectly aligned, as the macrocycles are twisted with a torsion angle of ca. $24^{\circ}$ (Figure $1 \mathrm{~b}$ ). Interestingly, the metallation of the porphyrin

a

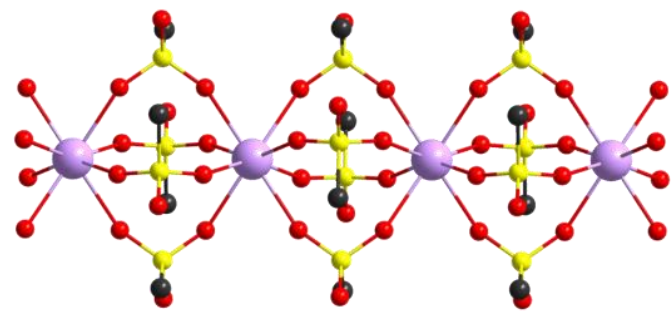

b

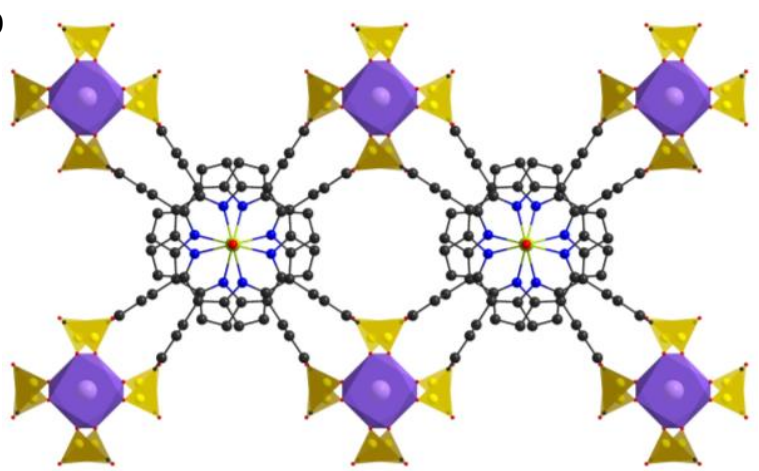

C

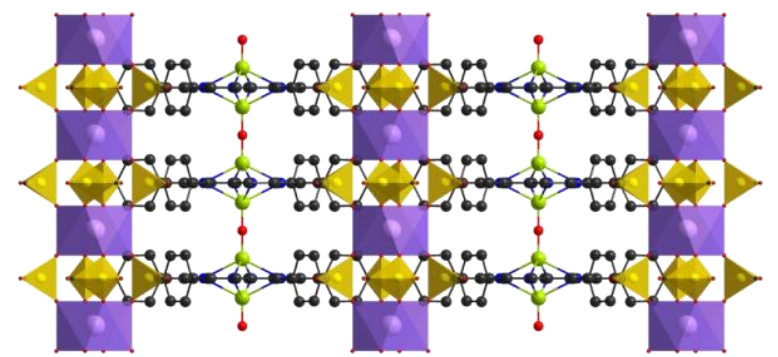

Figure 1: rod-like inorganic SBU in Ln-based MOF with TSPP (a), structural views of the vanadium oxo-bridged [Ln (VOTSPP) $\left.\mathrm{H}_{3} \mathrm{O}\right]_{n}$ MOF. Atomic colour code: $\mathrm{C}$ (black), $\mathrm{N}$ (blue), O (red), S (yellow), V (light green), Ln (purple).

*Note: for the sake of clarity, all crystal structures in Figures 1-13 are represented without the Hydrogen atoms. 

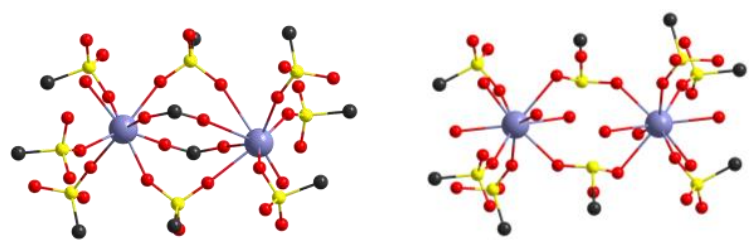

b

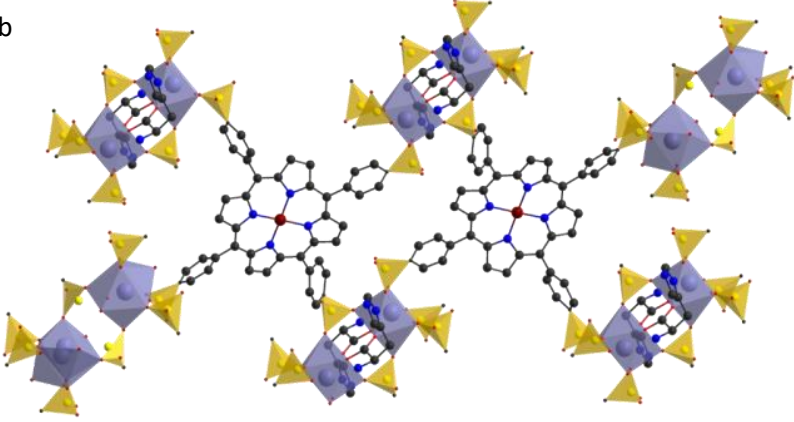

Figure 2: two types of dimers in the inorganic SBU (a) and structure (b) of $\left\{[\mathrm{Co}(\mathrm{TSPP})]_{2}\left[\operatorname{Ln}\left(\text { Histidine) }-\left(\mathrm{H}_{2} \mathrm{O}\right)\right]\left[\operatorname{Ln}\left(\mathrm{H}_{3} \mathrm{O}\right)_{3}\right]\right\}_{\mathrm{n}}\right.$. Atomic colour code: $\mathrm{C}$ (black), $\mathrm{N}($ blue $)$, $\mathrm{O}($ red), $\mathrm{S}$ (yellow), Co (dark red), Ln (purple).

core proceeds during the MOF synthesis if the free base porphyrin is reacted at the same time with $\mathrm{Ln}$ and a $3 \mathrm{~d}$ transition metal precursor, in hydrothermal conditions. When a metal is inserted inside the porphyrin, it is usually connected to the metal centre of the neighbouring macrocycle by either a bridging water molecule (divalent $\mathrm{Zn}$ and Co) or by an oxo ligand in case of V(IV) (Figure 1c). In case of a free base or divalent metalloporphyrin, the framework is anionic and the charge is balanced by an hydronium, giving the overall formula: [ $\left.\mathrm{LnM}(\mathrm{TSPP}) \mathrm{H}_{3} \mathrm{O}\right]_{n}{ }^{57,59-62}$ or : $\left[\mathrm{LnH}_{2}(\mathrm{TSPP}) \mathrm{H}_{3} \mathrm{O}\right]_{n}{ }^{54-56,58,63,64}$. For one of the reported compounds, a crystal structure of the $\mathrm{N}_{2}$ containing framework was solved, although in bulk measurements none of the sample proved to be intrinsically porous to $\mathrm{N}_{2}$. Their thermal stability reaches about $350{ }^{\circ} \mathrm{C}$ under air, as evidenced from thermogravimetric analysis (TGA). These samples were studied for their light absorption, luminescence, magnetic and electrochemical properties, but most of the characterizations were carried out after dissolution in organic solvents (methanol $(\mathrm{MeOH})$ or dimethyl sulfoxide (DMSO)). This implies that these coordination polymers are of a very limited chemical stability, and solid-state properties are not fully evidenced.

A mixed-ligand MOF is obtained when histidine is added to the reaction mixture. In this case, the amino acid gets coordinated to the $\mathrm{Ln}$ ion by its carboxylate part and a new series with chemical formula $\left\{[\mathrm{Co}(\mathrm{TSPP})]_{2}[\operatorname{Ln}(\right.$ Histidine)$\left.\left.\left(\mathrm{H}_{2} \mathrm{O}\right)\right]\left[\mathrm{Ln}\left(\mathrm{H}_{3} \mathrm{O}\right)_{3}\right]\right\}_{n}{ }^{65}$ or $\left\{\left[\mathrm{H}_{2}(\mathrm{TSPP})\right]_{2}\left[\mathrm{Ln}(\mathrm{Histidine})-\left(\mathrm{H}_{2} \mathrm{O}\right)\right]\left[\mathrm{Ln}\left(\mathrm{H}_{3} \mathrm{O}\right)_{3}\right]\right\}_{\mathrm{n}} 66,67$ are described. In this case, sulfonate coordination modes present more diversity and the asymmetric unit consists of two types of porphyrins and two types of disordered Ln. The Ln are arranged as dimers; in the first type of dimer each $\mathrm{Ln}$ is coordinated to three $O$ atoms from 2 bridging sulfonates that adopt $\eta^{2}, \eta^{1}, \mu^{2}$ coordination mode, two $O$ from two pending sulfonates and three $O$ from water molecules (Figure 2a). In the second type of dimer, Ln ions are bridged by two carboxylate groups from 2 histidine molecules, two bridging sulfonates in $\eta^{2}, \mu^{2}$ coordination mode, and their coordination sphere is completed by three pending sulfonates and two water molecules (Figure 2a). This way, the first type of dimers is composed of bridged 8-coordinated Ln ions in square antiprism geometry and for the second one 9-fold monocapped square antiprisms, this arrangement generates a 3D structure, with no evidenced porosity (Figure 2b). Again, as most of characterisations were carried out in solution, the chemical stability of these structures is supposed to be very limited and solid-state properties are not reported.

Demel et al. reported an interesting study, where by adjusting the synthesis parameters, either a 2D layered Ln hydroxide intercalated with TSPP or a 3-D MOF could be obtained ${ }^{52}$. Both syntheses proceed in water, and a very subtle variation in the synthesis conditions allows to obtain either pure layered hydroxide or a mixture with the MOF. The layered hydroxide sample is formed when the porphyrin is first converted to the tetrasodium salt by addition of $\mathrm{NaOH}$ and the $\mathrm{pH}$ of the reaction solution is 6.5-6.8 after Ln precursor addition. The MOF is formed by mixing the lanthanide salt with the protonated porphyrin salt TSPP. $2 \mathrm{HCl}$ and then adjusting the pH to $6.5-7.0$ by adding sodium hydroxide solution, and further purified by decantation. The as-prepared MOF is composed of distorted octahedral lanthanide oxo clusters $\left[\mathrm{Eu}_{6}\left(\mu_{6}-\mathrm{O}\right)\left(\mu_{3}-\mathrm{OH}\right)_{8}\left(\mathrm{H}_{2} \mathrm{O}\right)_{14}\left(\mathrm{SO}_{3}\right)_{8}\right]$ linked together by distorted TSPP molecules (Figure 3a). Each $\mathrm{Eu}_{6}$ cluster is composed of nine-coordinated Eu ions, linked to six porphyrins and each porphyrin coordinates three clusters, giving the chemical formula $\left[\left(\mathrm{H}_{2} \mathrm{TSPP}\right)_{2} \mathrm{Eu}_{6}\left(\mu_{6}-\mathrm{O}\right)\left(\mu_{3}-\mathrm{OH}\right)_{8}\left(\mathrm{H}_{2} \mathrm{O}\right)_{14}\right]$. In each porphyrin only three sulfonate groups are coordinated to $\mathrm{Eu}_{6}$ clusters; two of them are linked by two $\mathrm{O}$ atoms in either a chelating or bridging mode and the third sulfonate is pending. Noteworthy, the porphyrin cores are much more distorted than in the two previously discussed structures and they are stacked along one direction with a short 
a

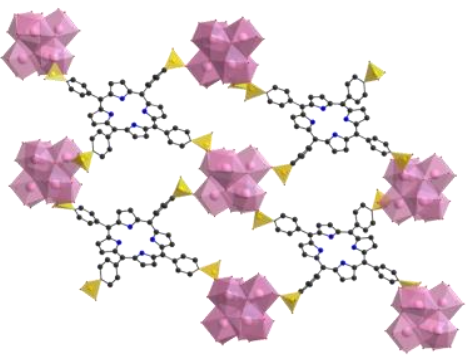

b
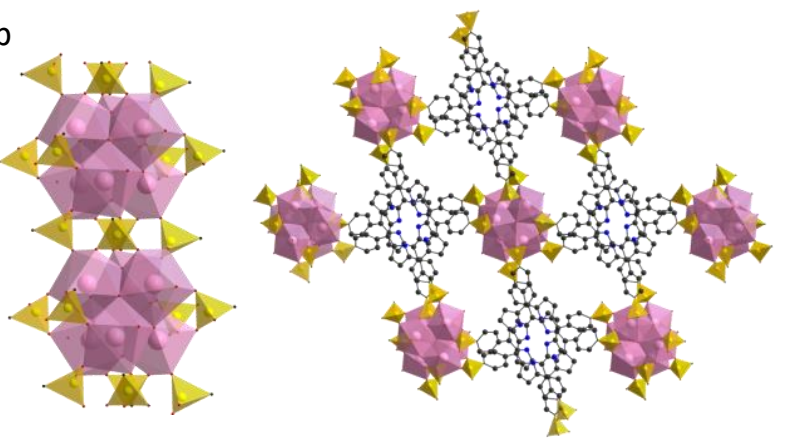

Figure 3: inorganic SBU and structural view of the as synthesised (a) and dehydrated

(b) Eu-TSPP MOF. Atomic colour code C (black), N (blue), O(red), S (yellow), Eu (pink).

interplanar distance of $3.8 \AA$. Upon dehydration, the MOF undergoes a phase change by losing some of the water molecules and the central $\mu_{6} \mathrm{O}$ atom (charge balance in not discussed by the authors), leading to eight-coordinated Eu centres in the trigonal prismatic SBU $\left[\mathrm{Eu}_{6}\left(\mu_{3}-\mathrm{OH}\right)_{8}\left(\mathrm{H}_{2} \mathrm{O}\right)_{2}\left(\mathrm{SO}_{3}\right)_{12}\right]^{2-}$ that are connected by 12 sulfonate groups from 12 porphyrinic linkers (Figure $3 \mathrm{~b}$ ). In this more compact structure, the $\mathrm{Eu}_{6}$ clusters are interlinked by four sulfonates groups in $\eta^{1}, \eta^{1}, \eta^{1}, \mu^{3}$ coordination mode and each porphyrin is coordinated to 4 clusters with two sulfonates in bidentate binuclear coordination mode and the two other ones in chelating mode. The inter-porphyrin distance is lowered to $3.65 \AA$ upon dehydration and the cavities shrink so no permanent porosity is accessible. Solid-state photoluminescence studies evidenced a relatively long lifetime for singlet oxygen generation by the MOF (23 $\mu$ s) compared to the layered hydroxide $(4 \mu \mathrm{s})$.

\section{Phosphonates}

Phosphonate group is a very strong anionic ligand and its diversity for metal coordination modes has appeared to be very useful for the construction of numerous inorganic-organic hybrid architectures ${ }^{68}$. The fundamental

a

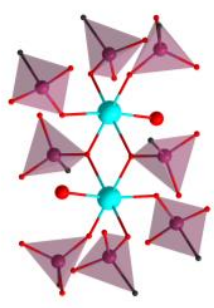

b

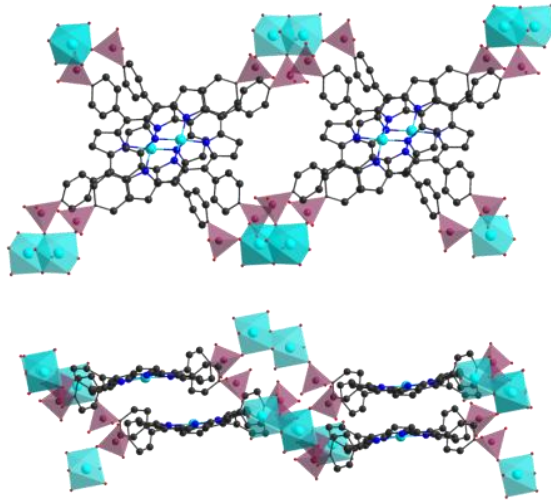

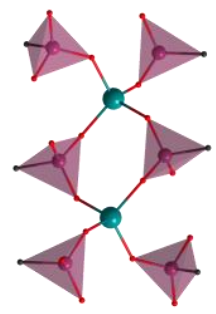

d

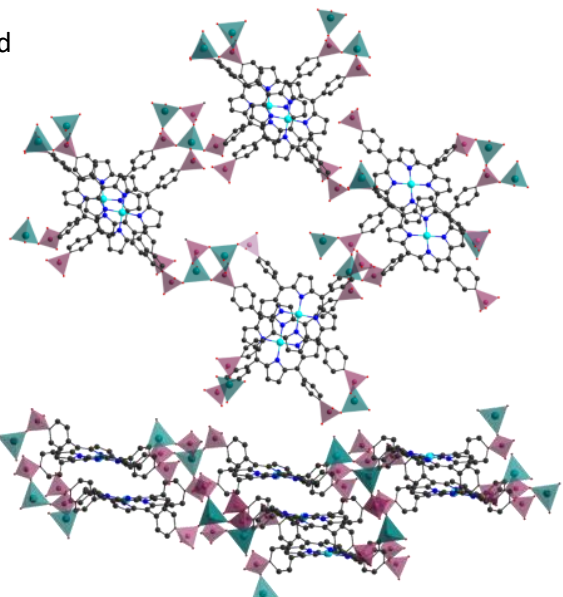

Figure 4: inorganic SBU (a) and structural views of Ni-CAU-29 (b), inorganic SBU (c) and structural views (d) of the Zn-based MOF IPCE-1 Ni. Atomic colour code: C (black), N(blue), $\mathrm{O}$ (red), $\mathrm{P}$ (burgundy), $\mathrm{Ni}$ (cyan), Zn (teal), the charge balancing ions are omitted for clarity.

differences with the carboxylate group lie in the fact that (a) three $\mathrm{O}$ atoms linked to the phosphorus lead to a higher 
diversity of binding modes, (b) higher charge leads to enhanced stability of coordination architectures, (c) two acidic protons with a noticeable pKa difference enable improved proton conductivity and structural diversities in phosphonates derived materials ${ }^{69-74}$. The presence of high charge density and several donor atoms in phosphonates favour coordination with high valent metal ions and lead to thermally and chemically stable metal phosphonate species. Yet the strong coordination is an obstacle for the formation of single crystals and thus rapid precipitation of insoluble phases is often observed ${ }^{75}$, requiring the use of advanced experimental tools to determine the crystal structure (such as electron diffraction). The number of reports of phosphonate based MOFs are only handful, but they appear to be effective for applications in proton conductivity, catalysis, storage, magnetism, biology and food chemistry ${ }^{72,76-78}$.

It was observed that the use of classical diphosphonic acid type linkers render mostly dense lamellar or pillared layered phosphonate metal organic solids ${ }^{42}$. Therefore, modifications in ligand design have become very crucial for the improvement of porosity. One of the effective approaches to overcome this problem is the introduction of planar tritopic and tetratopic linkers where the phosphonate groups are separated from each other by an angle of $90^{\circ}$ and $120^{\circ 42,71,79,80}$. In this aspect, 5,10,15,20-tetrakis(p-phenylphosphonic acid)porphyrin $\left(\mathrm{H}_{10} \mathrm{TPPP}\right.$ ) proved to be useful for generation porphyrin-based MOFs with significant porosity, as discussed below. Phosphonate porphyrinic MOFs have been prepared in a relatively large range of temperatures ( 80 to $200{ }^{\circ} \mathrm{C}$ ) using water, dimethylformamide (DMF), DMF/water or DMF/MeOH mixture as solvent. The use of small amount of strong acid or base and an excess of metal salt often led to significant improvement of crystallinity and reaction yield.

The first example was reported in 2018 by the group of N. Stock: $\mathrm{M}-\mathrm{CAU}-29$ with formula [M"I $\left(\mathrm{NiH}_{6} \mathrm{TPPP}\right)\left(\mathrm{H}_{2} \mathrm{O}\right)$ ], $(\mathrm{M}=$ $\mathrm{Mn}, \mathrm{Co}, \mathrm{Ni}, \mathrm{Cd}) .{ }^{42}$ This MOF is obtained from the Ni-metallated porphyrin and the structural analysis reveals that three-dimensional porous framework is based on edge-sharing octahedral dimeric SBU with formula $M_{2}(\mu-$ $\left.\mathrm{PO}_{3}\right)_{2}\left(\mathrm{PO}_{3}\right)_{6}\left(\mathrm{H}_{2} \mathrm{O}\right)_{2}$. The coordination sphere of each $\mathrm{M}(\mathrm{II})$ centre is completed by two bridging and three pending phosphonates from $\mathrm{NiH}_{6}$ TPPP2- and one axially coordinated water molecule (Figure 4a). Each dimer is connected to eight different $\mathrm{NiH}_{6} \mathrm{TPPP}^{2-}$ units. Among three $\mathrm{O}$ atoms present in the phosphonate linker, only one oxygen atom gets coordinated to the $\mathrm{M}(\mathrm{II})$ centre. Here, the porphyrins are located at parallel planes with an inter-core distance of $\sim 5.42 \AA$ (Figure 4b). CAU-29 displays thermal stability up to $350{ }^{\circ} \mathrm{C}$ in air and chemical stability in several organic solvents (dichloromethane, acetone, ethanol, and acetic acid) and water at $\mathrm{pH}$ range 1-11. The MOF loses its crystallinity in $0.1 \mathrm{M}$ phosphate buffer $(\mathrm{pH}=7)$. This material is only moderately porous with BET Surface Area (BET $\mathrm{SA})$ of $0,90,145$ and $180 \mathrm{~m}^{2} \mathrm{~g}^{-1}$ for $\mathrm{Ni}-, \mathrm{Mn}-$, Co- and Cd-CAU-29 respectively, due to the small pore sizes $(2.8 \times 5 \AA$ and $3.8 \times 3.8 \AA$ ). Yet $\mathrm{Ni}-\mathrm{CAU}-29$ showed the highest water uptake of $181 \mathrm{mg} \mathrm{g}^{-1}$ and a protonic conductivity of 5.62 $\times 10^{-6} \mathrm{~S} \mathrm{~cm}^{-1}$ at $80^{\circ} \mathrm{C}$ and $90 \%$ relative humidity.

A different dimeric inorganic SBU was reported for the three dimensional IPCE-1Ni MOF with molecular formula $\left[\mathrm{Zn}_{3}\left(\mathrm{NiH}_{3} \mathrm{TPP}\right)_{3} \cdot 9 \mathrm{DMA} \cdot 3 \mathrm{DMF} \cdot 17 \mathrm{H}_{2} \mathrm{O}\right]^{81}$ (DMA: dimethylamonium). Here, the inorganic 6-connected SBU is formulated $\mathrm{Zn}_{2}\left(\mu-\mathrm{PO}_{3}\right)_{2}\left(\mathrm{PO}_{2} \mathrm{OH}\right)_{4}$, where each zinc tetrahedron is coordinated with two completely deprotonated bridging phosphonates and two partially deprotonated pending phosphonates from $\mathrm{Ni}^{-} \mathrm{H}_{3}$ TPPP5-, linked in a monodentate fashion (Figure 4c). Each dimer is connected to six different $\mathrm{Ni}^{-\mathrm{H}_{3} \text { TPPP }}{ }^{5}$ - units and the total negative charge of the framework is balanced by DMA cations occupying the cavities. Interestingly, each porphyrin acts as a 3-connected node which is very rare for this tetratopic ligand, and overall the MOF exhibits a rare $(3,6)$-connected flu topology. Similarly to CAU-29 the porphyrins are stacked closely to each over with an inter-core distance of $\sim 4.98$ $\AA$ (Figure 4d). The non-coordinated phosphonate takes part in $\mathrm{H}$-bonding with the neighbouring porphyrin unit and

a

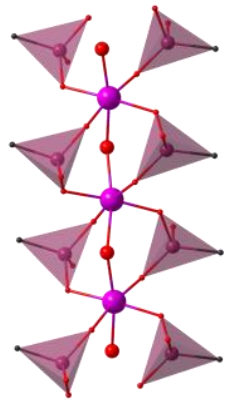

b

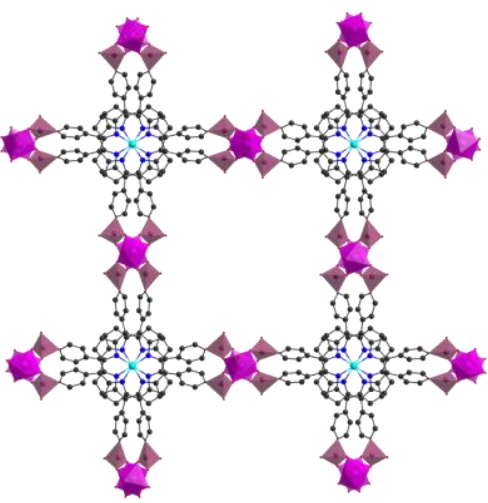

c

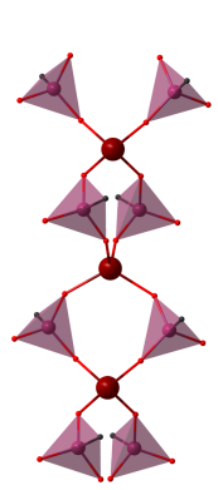

d

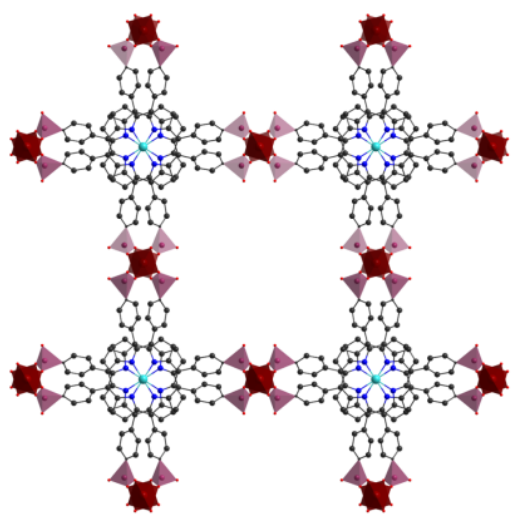

Figure 5: inorganic SBU (a) and structural view (b) of Zr-CAU-30, and inorganic SBU (c) and structural view (d) of Co-CAU-36. Atomic colour code: C (black), N(blue), O (red), P (burgundy), Zr (magenta), Co (dark red).

accounts for the high proton conductivity value of this $\operatorname{MOF}\left(1.55 \times 10^{-3} \mathrm{~S} \mathrm{~cm}^{-1}\right.$ at $75^{\circ} \mathrm{C}$ and $80 \%$ relative humidity). 
a

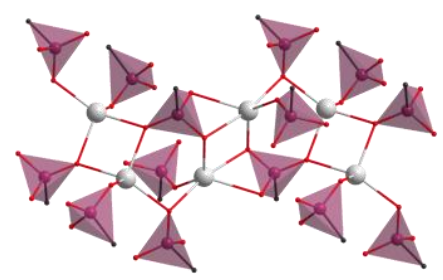

b

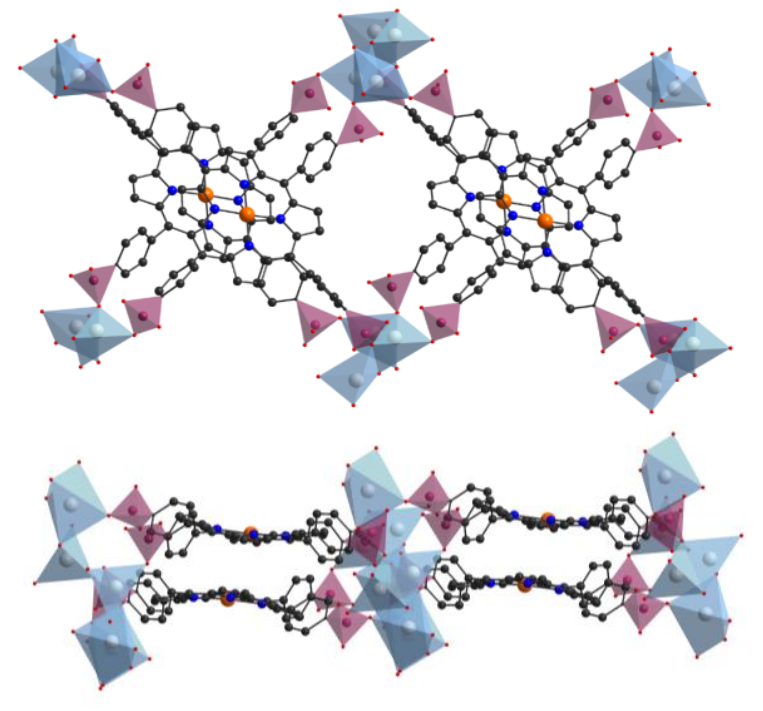

Figure 6: inorganic SBU (a) and structural views (b) of GTUB-1. Atomic colour code C (black), $\mathrm{N}$ (blue), O (red), $\mathrm{P}$ (burgundy), $\mathrm{Cu}$ (orange), $\mathrm{Na}$ (ice blue), charge compensating counterions are omitted for clarity.

IPCE-1Ni retains its crystallinity after heating up to $300{ }^{\circ} \mathrm{C}$ in air. The porosity is here again very moderate towards $\mathrm{CO}_{2}$ with a BET SA of $209 \mathrm{~m}^{2} \mathrm{~g}^{-1}$.

Very recently, this work was further extended through linker design for improved proton conductivity ${ }^{82}$. The authors reported IPCE-2Ni MOF, based on $\mathrm{Zn}(\mathrm{II})$ and the meso-tetra(metaphosphonatophenyl)porphyrinate linker with the molecular formula $\left[\mathrm{Zn}_{3}\left(\mathrm{NiH}_{2} \mathrm{TmPPP}\right)\left(\mathrm{NiH}_{4} \mathrm{TmPPP}\right)\left(\mathrm{NiH}_{5} \mathrm{TmPPP}\right) \cdot 7 \mathrm{DMA} \cdot \mathrm{DMF} \cdot \mathrm{H}_{2} \mathrm{O}\right.$ ] (where $\mathrm{NiH}_{\mathrm{x}} \mathrm{TmPPP}$ stands for partially deprotonated ligand). By moving the phosphonate from the para to the meta position, the size of the channels decreases inducing a strong hydrogen bonding with charge compensating DMA cations inside the pores and favouring the proton transfer process $\left(10^{-2} \mathrm{~S} \mathrm{~cm}^{-1}\right.$ at $75^{\circ} \mathrm{C}$ and $95 \%$ relative humidity). In IPCE-2Ni the inorganic $\mathrm{SBU}$ is built from isolated tetrahedral $\mathrm{Zn}(\mathrm{II})$ sites coordinated by partially deprotonated phosphonates, each porphyrin acts as a 3-connected node leading to a 3-D anionic MOF with small pores and a BET SA of only $19.8 \mathrm{~m}^{2} \mathrm{~g}-$ 1. This framework shows thermal stability up to $350^{\circ} \mathrm{C}$ and is stable in water and organic solvents.

$\mathrm{N}$. Stock and co-workers have further extended their work for the development of tetravalent metal phosphonate porphyrinic frameworks. The combination of $\mathrm{Hf}(\mathrm{IV})$ and $\mathrm{Zr}(\mathrm{IV})$ with $\mathrm{Ni}-\mathrm{H}_{8} \mathrm{TPPP}$ leads to the formation of highly porous MOFs, M-CAU-30, with formula $\left[\mathrm{M}^{\prime \mathrm{I}}{ }_{2}\left(\mathrm{NiH}_{2} \mathrm{TPPP}\right)(\mathrm{OH} / \mathrm{F})_{2}\right] \cdot \mathrm{xH}_{2} \mathrm{O}(\mathrm{M}=\mathrm{Zr}, \mathrm{Hf})^{83}$. The inorganic SBU in the 3D MOF consists of corner sharing chain of $\mathrm{Zr}$ octahedra with the chemical formula $\mathrm{Zr}\left(\mu-\mathrm{PO}_{3}\right)_{4}(\mu-\mathrm{OH})_{2}$. Each $\mathrm{Zr}$ is coordinated by four bridging phosphonates from four different $\mathrm{NiH}_{4}$ TPPP4- and two $\mathrm{OH}^{-}$or $\mathrm{F}^{-}$- bridging ions (Figure $5 \mathrm{a}$ ). Therefore, each phosphonate function bridges two $\mathrm{Zr}$ atoms, so each porphyrin is connected to eight $\mathrm{Zr}$ ions. This SBU was previously observed for other $\mathrm{Zr}$-phosphonate MOFs, but each $\mathrm{Zr}$ atom was connected to six oxygen atoms from six different phosphonate groups. ${ }^{84-87}$ In this compound, the metalloporphyrins are closely stacked with an inter-core separation of $\sim 3.83 \AA$ (Figure $5 b$ ). The strong coordination between tetravalent metal ions and phosphonates offers higher thermal and chemical stability when compared to CAU-29. Indeed, CAU-30 is stable up to $400{ }^{\circ} \mathrm{C}$ in air, remains crystalline in organic solvents and in $0-12 \mathrm{pH}$ range in water, as well as in $0.1 \mathrm{M}$ phosphate buffer $(\mathrm{pH}=7)$ for $24 \mathrm{~h}$ at room temperature. The structure is porous with 1D channels with $1.3 \mathrm{~nm}$ pore diameter and a BET SA of $970(\mathrm{Zr})$ and $910(\mathrm{Hf}) \mathrm{m}^{2} \mathrm{~g}^{-1}$. Porphyrinic redox activity was evidenced for $\mathrm{Zr}$-CAU-30 by solid-state cyclic voltammetry.

SBU featuring 1D chain structure was also observed for $\left[\mathrm{CO}_{2}\left(\mathrm{NiH}_{4} \mathrm{TPPP}\right)\right] \cdot 2 \mathrm{DABCO} \cdot 6 \mathrm{H}_{2} \mathrm{O}$ (DABCO: 1,4diazabicyclo[2.2.2] octane), namely Co-CAU-36 ${ }^{88}$. Here, the inorganic SBU is based on a chain of corner-sharing $\mathrm{CoO}_{4}$ tetrahedra with the formula $\mathrm{Co}\left(\mu-\mathrm{PO}_{3}\right)_{4}$ (Figure $5 \mathrm{c}$ ). Each $\mathrm{Co}$ is coordinated by four bridging phosphonates from four different $\mathrm{Ni}_{-} \mathrm{H}_{4}$ TPPP4- and each porphyrin is connected to eight Co centres resulting in a 3D porous framework with 1D channels and $9 \AA$ Å pore diameters (Figure $5 \mathrm{~d}$ ). Here the porphyrins are stacked similarly to CAU-30 with an inter- 
porphyrin shortest distance of $\sim 4.48 \AA$, although the topologies of the two frameworks differ (see below). DABCO and water molecules are located inside the pores of the framework. It is worth mentioning that similar structural motif was previously reported for a $\mathrm{N}, \mathrm{N}^{\prime}$-piperazinebis(methylenephosphonic acid) based framework ${ }^{89}$. CAU-36 shows an intrinsic porosity with a BET SA of $700 \mathrm{~m}^{2} \mathrm{~g}^{-1}$ and thermal stability up to $360^{\circ} \mathrm{C}$ in air, whereas the chemical stability is very limited.

An alkali-phosphonate porous MOF with molecular formula [ $\left.\mathrm{Na}_{2} \mathrm{Cu}\left(\mathrm{H}_{4} T P P P\right)\right]$. DMA, namely GTUB-1, was reported in 2019 by Maares and coworkers ${ }^{80}$. Its inorganic SBU exhibits a chain structure featuring two types of Na centres; a penta coordinated $\mathrm{Na}$ with four oxygen atoms from two $\mu$-bridging and one terminal $\mathrm{PO}_{3} \mathrm{H}$ and a tetra coordinated $\mathrm{Na}$ linked to three oxygen atom of three bridging $\mu-\mathrm{PO}_{3}$ and one terminal $\mathrm{PO}_{3} \mathrm{H}$ (Figure $6 \mathrm{a}$ ). The distance between the $\mathrm{Cu}$ (II) porphyrins at adjacent layers amounts to $\sim 5.03 \AA$ (Figure $6 \mathrm{~b}$ ). Dimethylamonium ions are located in the rectangular pores of the $3 \mathrm{D}$ framework. This MOF is thermally stable up to $360^{\circ} \mathrm{C}$ in air and shows a BET SA of 698 $\mathrm{m}^{2} \mathrm{~g}^{-1}$.

One last example of $\mathrm{Ln}$-based MOF was reported, constructed from the free-base phosphonate porphyrin, $\mathrm{H}_{10}$-TPPP and formulated as $\left[\mathrm{Ln}\left(\mathrm{H}_{9} \mathrm{TPPP}\right)\left(\mathrm{H}_{2} \mathrm{O}\right)_{\mathrm{x}}\right] \mathrm{Cl}_{2} \cdot \mathrm{yH}_{2} \mathrm{O}^{3}$. This solid was obtained as nanoparticles, although porphyrins are not metallated in this case, activity in heterogeneous catalysis for the sulfoxidation of thioanlisole by $\mathrm{H}_{2} \mathrm{O}_{2}$ is described (a reaction known to be catalysed by $\mathrm{Fe}$ and $\mathrm{Mn}$ porphyrins ${ }^{90}$ ). Furthermore, as per fluorescence quenching behaviour, it showed some potential for sensing of nitroaromatic compounds. Nevertheless, no crystal structural data was provided.

\section{Phenolates}

Polyphenol occurrence in biological systems brought considerable interest to chemists for bio-inspired design and synthesis of materials, coatings and biomimetic molecules ${ }^{91}$. Indeed, naturally occurring polyphenols are widely found in flavonoids and tannins, where they play an important role given their anti-oxidant activity ${ }^{92}$. These polyphenols are based on the catechol (dihydroxyphenyl, Cat) and gallol (trihydroxyphenyl, Gal) functions that generally bind in a polydentate chelating mode to a metal ion, leading to enhanced stability of the resulting coordination architecture ${ }^{93}$ and to remarkable adhesive properties on a macromolecular scale ${ }^{94}$.

From the chemical point of view, catechol and gallol bearing molecules are complex systems as they show at the same time coordinating functionalities, redox activity and acido-basicity. Phenolic protons display pKa values in the range $9-14^{95}$ therefore, deprotonated polyphenols are hard Lewis bases that are stronger than the carboxylate counterparts, leading to more stable coordination bonds with hard Lewis acids, among which $\mathrm{Fe}^{3+}$ polyphenolates have been extensively studied and very high stability constants are reported ${ }^{96}(\log \beta$ 20-40). The $\mathrm{pH}$ range is affecting the protonation state of the ligand, note that polyphenols are known to commonly bind to metals both in their neutral and deprotonated state ${ }^{97-99}$, which is rare in case of carboxylic acids. The $\mathrm{pH}$ change can therefore affect the ligand to metal ratio in the resulting compound. From the redox point of view, polyphenols are non-innocent functionalities, as they can be oxidised to semiquinone and further to quinone, therefore sometimes it can be tricky to unambiguously establish the exact protonation and redox state of the coordinating moiety when using a polyphenol ligand. The redox activity of polyphenols

(a)
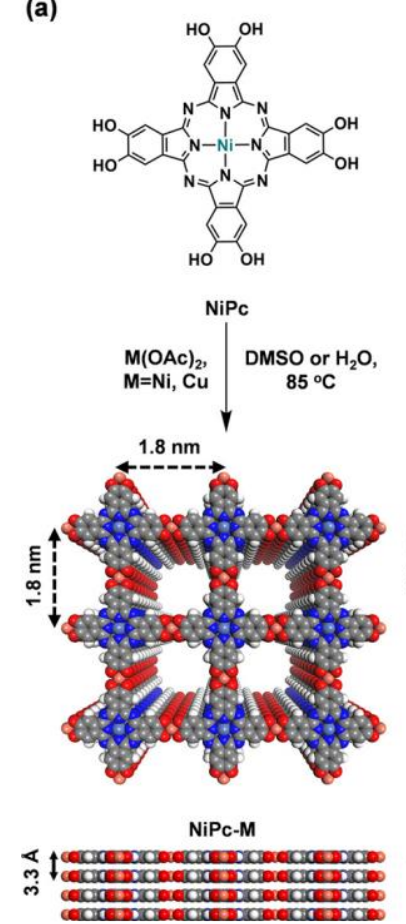

Figure 8: Synthetic scheme for isoreticular phthalocyanine and naphthalocyaninebased MOFs (a) NiPc-M and (b) Ni-NPc-M from reference 105.
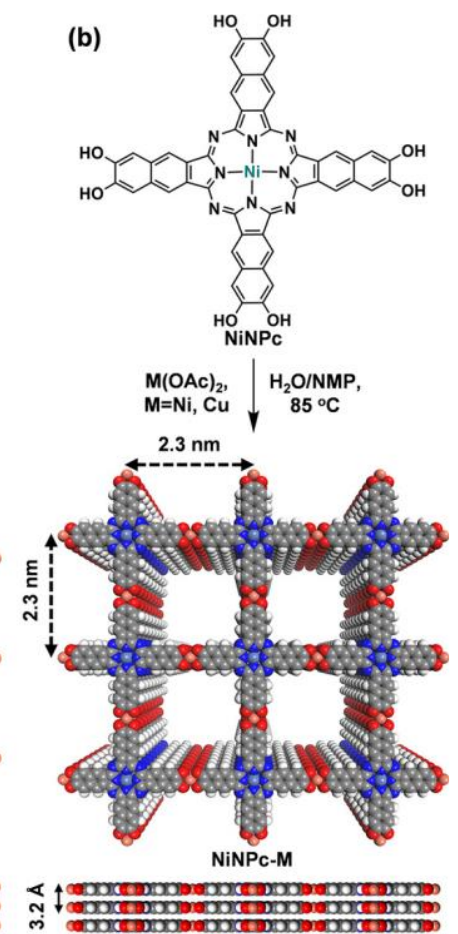

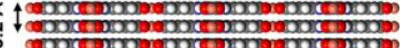

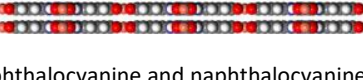




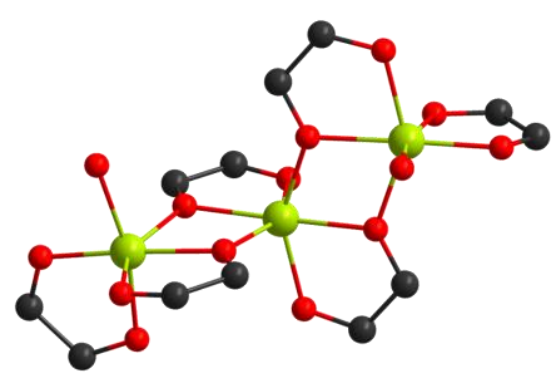

b

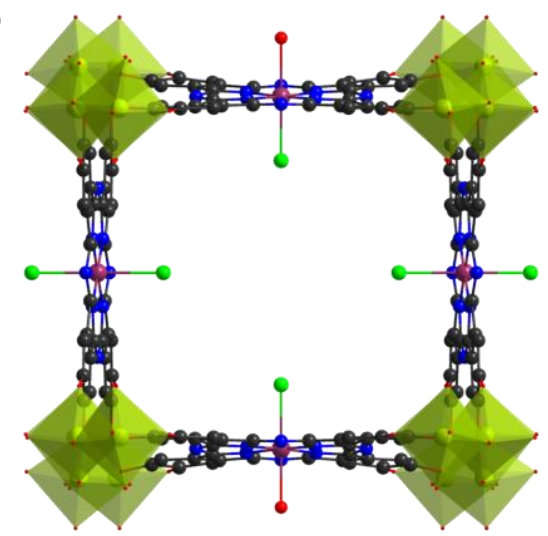

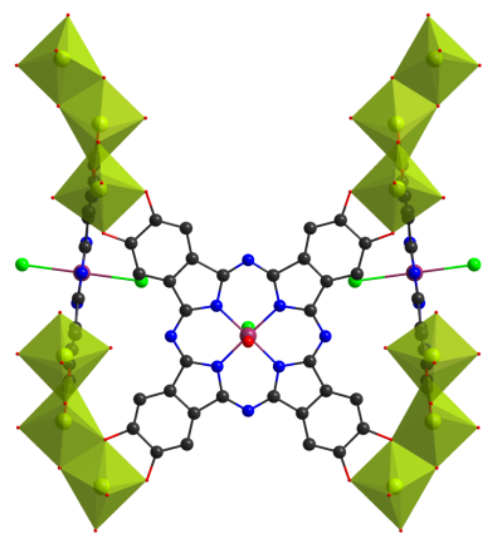

Figure 7: inorganic SBU (a) and structural views in ( $a, b)$ plane (b) and (a,c) plane (c) of MOF-1992. Atomic colour code C (black), N(blue), O (red), Fe (olive), $\mathrm{Cl}$ (green), charge compensating counterions are omitted for clarity.

favourably contributes to the charge transfer and can often lead to electrically conductive hybrid molecular architectures ${ }^{100,101}$.

Regarding the catechol-based porphyrin and phthalocyanine MOFs very little structural data is available so far. Indeed, only one structure was solved from single crystal diffraction, corresponding to the MOF-1992 reported recently by Yaghi et al. ${ }^{19}$ based on the catechol Co-phthalocyanine (CoTCatPc) and Fe. Single crystals were obtained upon reacting $\mathrm{H}_{8} \mathrm{CoTCatPc}$ with $\mathrm{FeCl}_{2}$ in solvothermal conditions in DMF/water/MeOH mixture. In MOF-1992 Fe(III) ions are octahedrally coordinated and assemble into trimeric inorganic units formulated $\mathrm{Fe}_{3}(\mathrm{Cat})_{6}\left(\mathrm{H}_{2} \mathrm{O}\right)_{2}$. The central Fe is coordinated to 4 catechol groups from 4 different phthalocyanines, two of which are $\eta^{2}$ chelating and the other two are in bridging mode. The edge Fe centres are linked to three catechol moieties from three different phthalocyanines, one in a chelating $\eta^{2}$ mode, the two other ones are $\eta^{2}$ and $\eta^{1}$ bridging towards the central Fe. The coordination sphere of the edge metallic centres is then completed by a water molecule (Figure 7a). Each phthalocyanine is connected to four different iron trimers generating an anionic 3-D framework with a roc topology (Figures $7 \mathrm{~b}$ and $\mathrm{c}$ ). The charge is balanced by extra-framework Fe(III) ions giving an overall chemical formula $\left[\mathrm{Fe}_{6}\left(\mathrm{OH}_{2}\right)_{4}(\mathrm{CoTcatPc})_{3}\right] \cdot\left[\mathrm{Fe}_{3}(\mathrm{OH})_{3}\left(\mathrm{OH}_{2}\right)_{2}\right]$. MOF-1992 is an intrinsically porous material with a BET SA of $1471 \mathrm{~m}^{2} \mathrm{~g}^{-1}$, a main pore size of $10.7 \AA$ and a secondary pore of $14.6 \AA$. The charge compensating cations could be exchanged by $\mathrm{Mg}^{2+}$, resulting in isostructural MOF with a similar BET SA and pore size. MOF-1992 is electrically conductive as deduced from qualitative measurements on isolated single crystals. The charge transfer properties were valuable for the electrocatalytic activity in $\mathrm{CO}_{2}$ reduction to $\mathrm{CO}$ in water.

Besides this three-dimensional compound, a series of reports deal with 2D layered MOFs based on the catechol MPc linker with various metals as inorganic nodes. Generally, all these compounds were synthesized using similar solvothermal conditions with DMF/water or n-methyl-2-pyrrolidone (NMP)/water mixtures as solvent. Although the crystallinity of the resulting compounds is low, simulation of the crystal structure affords a structural model of eclipsed molecular layers in AA stacking mode, with a square planar metal coordination geometry for the inorganic SBU, each metal being linked to two catecholates originating from two phthalocyanine ligands (Figure 8). First, the group of Kimizuka reported the copper-based MOF Cu-CuPc anionic framework containing ammonium ions inside the pores ${ }^{102}$. This compound is porous with a BET SA of $360 \mathrm{~m}^{2} \mathrm{~g}^{-1}$ and both micro and mesoporosity are observed. The micropores originate from the 2D structure when the mesopores are assumed to originate from the grain boundaries between aggregated MOF nanoparticles. They explored the electrical conductivity of this compound on a pressed pellet and reported a value of $1.6 \times 10^{-6} \mathrm{~S} \mathrm{~cm}^{-1}$ at $80^{\circ} \mathrm{C}$. This conductivity value prompted to test this MOF as a cathode for Li ion battery where it showed high capacities and and decent capacity retention upon cycling. Later on, the group of Feng reported the electrochemical performance of the isostructural MOF based on the CuTCatPc and $\mathrm{Fe}$ as a cathode in sodium-iodine batteries ${ }^{103}$. The loading of the $\mathrm{Fe}_{2}-\mathrm{O}_{8}-\mathrm{CuPc}$ with $\mathrm{I}_{2}$ molecules results in $\left(\mathrm{Fe}_{2}-\mathrm{O}_{8}-\mathrm{CuTCatPc} / \mathrm{I}_{2}\right)$ isostructural phase with an increased electrical conductivity measured on pressed pellets; values as high as $9.7 \mathrm{mS} \mathrm{cm} \mathrm{cm}^{-1}$ are reported at room temperature. X-ray Photoelectron spectroscopy (XPS) measurements suggest that iodine is adsorbed as a free molecule and is not bound to any metal inside the MOF. Similar capacities are reported as in the study of Kimizuka et al. and more importantly a suitable electrochemical stability is reached in sodium-iodine battery tests. Specifically, the MOF is favourable to prevent polyiodide dissolution into the electrolyte, this property was rationalised by the polyiodide binding by square planar Fe atoms. The same group also reported $\mathrm{Co}_{2}-\mathrm{O}_{8}-\mathrm{CUTCatPc}$ MOF with a BET SA of $412 \mathrm{~m}^{2} \mathrm{~g}^{-1}$, exhibiting micro and mesoporosity $^{104}$. They mixed the MOF with carbon nanotubes to use the mixture as electrocatalyst for oxygen 
reduction reaction in alkaline media. An efficient, mainly 4 electrons, reduction process is demonstrated with remarkable onset potential $\left(E_{1 / 2}=0.83 \mathrm{~V}\right.$ vs. $\left.\mathrm{RHE}\right)$ and current density values.

An isoreticular synthesis strategy allowed access to an extended 2-D layered structure, reported by Mirica et al ${ }^{105}$. The authors report isotopic 2D structures using both $\mathrm{Ni}$-phthalocyanine and $\mathrm{Ni}$-naphthalocyanine functionalised with catechol groups in association with $\mathrm{Ni}$ and $\mathrm{Cu}$ to form isoreticular MOFs (Figure 8). Interestingly, electron paramagnetic resonance (EPR) and XPS analysis reveals that in NiPc-Cu MOF the ligand is mainly in its semiquinone form when the naphthalocyanine phase displays the ligand in further oxidised, mixed semiquinone and quinone state. Lower BET SA values are reported, between 101 and $284 \mathrm{~m}^{2} \mathrm{~g}^{-1}$. The electrical conductivity was measured again on pressed pellets and values between $10^{-4}$ and $10^{-2} \mathrm{~S} \mathrm{~cm}^{-1}$ are reported. The MOFs were suspended in water and drop casted onto chemresistive device made of interdigitated gold electrodes. The sensing properties were evaluated towards the detection of $\mathrm{NH}_{3}, \mathrm{H}_{2} \mathrm{~S}$ and $\mathrm{NO}$ gases and high sensitivity for the latter two is reported. This property is rationalised in terms of charge transfer interactions between the reducing $\mathrm{H}_{2} \mathrm{~S}$ and oxidising NO vapours and the redox active semiquinone moieties in the linker; charge transfer modulates the overall conductivity, allowing chemresistive sensing.

Although this last example is not based on the O-donor ligands, it is worth mentioning here that very similarly to the strategy of building 2D-frameworks with catecholate phthalocyanines, Jia et al reported a 2D material obtained from the ortho-phenylenediamine functionalized phthalocyanine $(2,3,9,10,16,17,23,24$-octaamino-

phthalocyaninato nickel(II) ( $\left.\mathrm{NiPc}-\mathrm{NH}_{2}\right)$ ), and $\mathrm{Ni}(\mathrm{II}) .{ }^{106}$ Here again the coordination polymer is poorly crystalline and a square planar geometry for the inorganic building unit is proposed with an eclipsed AA stacking arrangement of the MOF layers. During the synthesis the ortho-phenylenediamine groups are converted to the ortho-semiquinone diimine, leading to a neutral diradical framework. This compound could be grown as thin films, displayed high electrical conductivity $\left(0.2 \mathrm{~S} \mathrm{~cm}^{-1}\right)$ and activity in water oxidation reaction electrocatalysis.

Regarding catechol porphyrin-based frameworks, no proper structural data is reported so far. Coordination polymers obtained from this ligand with a number of metallic ions were rather used as precursors for thermolysis ${ }^{107,108}$, and more recently Ti-based compounds were explored in their pristine form and associated to cobalt sulfide for electrocatalytic applications. ${ }^{109,110}$ In all the studies, very poor crystallinity is achieved after solvothermal reaction and a square planar coordination geometry for the metallic ion is speculated, whatever its nature and oxidation state $(\mathrm{Fe}, \mathrm{Co}, \mathrm{Ni}, \mathrm{Cu}, \mathrm{Ti})$. Moderate porosity is reported for the pristine coordination polymers (200-380 $\mathrm{m}^{2} \mathrm{~g}^{-1}$ ); an increase in porosity is usually achieved after thermolysis, and the derived materials were studied for their electrochemical properties such as battery or supercapacitor active materials ${ }^{107}$ or electrocatalysts, ${ }^{108}$ yet no structure-activity relation can be outlined after the thermal treatment. In case of $\mathrm{Ti}$, a coordination compound was synthesised in DMF and studied for electrochemical applications by the group of Zhu. ${ }^{109}$ The electrocatalytic activity of the pristine material was tested for hydrogen evolution reaction (HER) in acidic aqueous conditions and for oxygen evolution reaction (OER) in basic solution. For both reactions, good current densities were achieved at low overpotentials. Mechanistic insights suggest that efficient charge transfer between the porphyrin and Ti leads to push-pull architecture with improved activity. ${ }^{109}$ This material was further explored in combination with cobalt sulfide for OER. Incorporation of the coordination polymer significantly promoted the OER performance ${ }^{110}$ which was rationalised in terms of increased porosity leading to a greater number of active sites and faster mass transfer, preferential adsorption sites for intermediate species, larger Co(III) content and improved conductivity of the cobalt sulfide species in the composite material.

When considering the gallol based frameworks, only porphyrinic MOFs are reported and all are based on rod like Zr-oxo or Ln-oxo chain SBUs. First structural data were reported by Mouchaham et al. with isotopic compounds obtained by reacting the tetragallol porphyrin $\mathrm{H}_{14}$ TGalPP (Figure 9b) with either $\mathrm{Zr}$ or lanthanide chloride salts in DMF/water mixtures ${ }^{111}$. In case of La, single crystals suitable for diffraction and structure solution can be obtained when in case of $\mathrm{Zr}$, crystallites of $200-400 \mathrm{~nm}$ are recovered and the structure could be solved from powder diffraction data. The inorganic SBU corresponds to the $\mathrm{Zr}(1,2,3 \text {-trioxobenzene })_{4}$ rod-like motif which was earlier reported for the robust MIL-163 structure ${ }^{99}$. Interestingly, this SBU could be extended to trivalent metals that accommodate 8-fold coordination geometry such as $\mathrm{La}, \mathrm{Ce}$ and $\mathrm{Y}$. These rods are built up from edge-sharing $\mathrm{MO}_{8}$ dodecahedra, each metal being chelated by four gallol groups from four different porphyrins (Figure 9a). Each porphyrin is linked to four different rods generating a 3-D network with porphyrinic macrocycles lying in an eclipsed manner orthogonally to the inorganic chains with an inter-porphyrin core distance of ca. $7.5 \AA$ (Figure $9 \mathrm{~d}$ and e). The gallol group is partially deprotonated, as one hydrogen remains on the meta $\mathrm{OH}$ group and ensures the charge balance. Dimethylamine molecules strongly interact with the acidic $\mathrm{OH}$ groups via hydrogen bonding. In case of lanthanide-based framework, it is likely that gallol groups are deprotonated to a lesser extent. Despite the same topology, major stability differences are evidenced between the $\mathrm{Zr}$ and lanthanide-based frameworks. Indeed, ZrMIL-173 is an intrinsically porous MOF with a BET SA of $850 \mathrm{~m}^{2} \mathrm{~g}^{-1}$, from $\mathrm{N}_{2}$ sorption isotherms, when MIL-173(La) and MIL-173(Ce) collapse upon vacuum activation. Chemical stability was further investigated in water and in presence of phosphate competing complexing agents. Only the $\mathrm{Zr}$-based MOFs showed excellent chemical 
robustness as evidenced from PXRD and nitrogen sorption measurements. In MIL-173 frameworks, the porphyrin remains in its free base form that allowed its post-synthesis metalation with Co. The Co-containing compound displayed heme-like aerobic oxidation of hydrocarbons through oxygen activation and electron transfer in a solventless process. Given the impressive robustness of the Zr-gallate framework, this material was further studied by several groups for a number of properties. We could demonstrate its compatibility with an ALD-derived technique for post-synthesis modification on both the phenolic and pyrrolic reactive sites ${ }^{112}$. Vapour phase infiltration was achieved using two kinds of precursors: diethylzinc (DEZ) and trimethylaluminium (TMA). Both reactive precursors could efficiently diffuse inside the porous framework and react at both reactive sites leading to a successful metal insertion in a self-limiting manner, with preservation of the framework integrity.

Later on, Lin et al. reported the same structure based on $\mathrm{Zr}$ (named ZrPP-1), and extended the MOF series to an isoreticular ZrPP-2 framework that is built up from the extended 5,10,15,20-tetrakis(3,4,5trihydroxybiphenyl)porphyrin linker ${ }^{113}$. The robustness of this material is highlighted again through resistance to immersion in $20 \mathrm{M} \mathrm{NaOH}$ solution. Free base and metallated ZrPP-1 materials are obtained by inserting various metals in the porphyrinic core prior to MOF synthesis. In case of $\mathrm{Co}$, efficient $\mathrm{CO}_{2}$ photoreduction to $\mathrm{CO}$ and $\mathrm{CH}_{4}$ was demonstrated, and attributed to the favourable eclipsed packing of metalloporphyrins and the well-suited distance between the $\mathrm{Co}$ centres that stabilizes the $\mathrm{CO}_{2}$-porphyrin adduct. The same group later took advantage of the presence of acidic protons and extraframework dimethylamine to explore the protonic conduction in ZrPP-1 and ZrPP-2. Measurements on pellets provided high conductivity values of $8.0 \times 10^{-3}$ and $4.2 \times 10^{-3} \mathrm{~S} \mathrm{~cm}^{-1}$, respectively, under $98 \% \mathrm{RH}$ at $25^{\circ} \mathrm{C}$ with low activation energies, possibly associated with a Grotthus hoping mechanism. Later on, the same group investigated the optical limiting properties of ZrPP-1 and ZrPP-2 frameworks with different

a

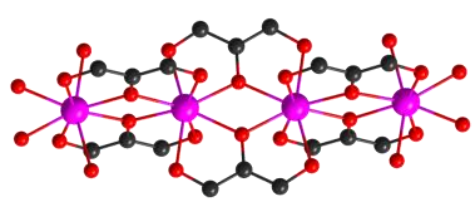

d

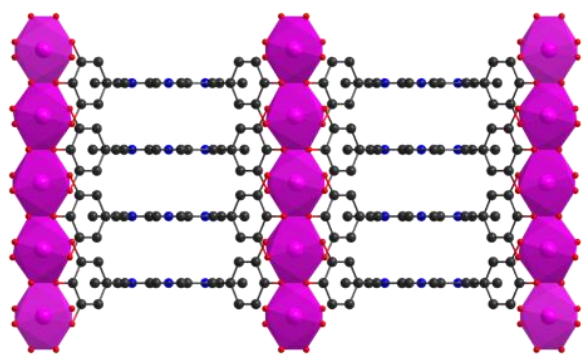

b
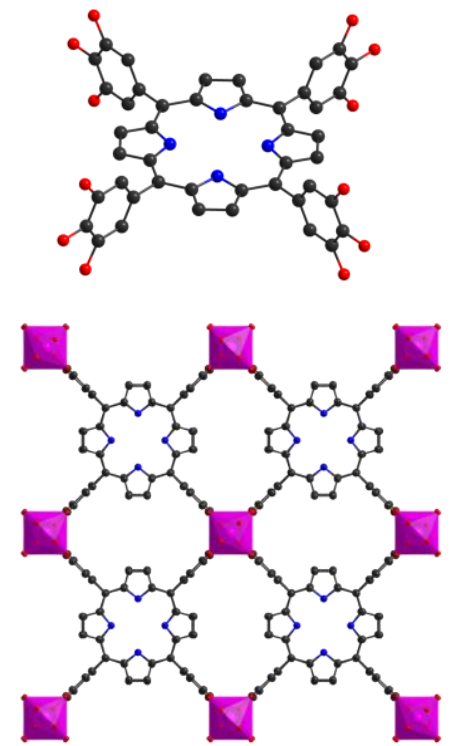

c
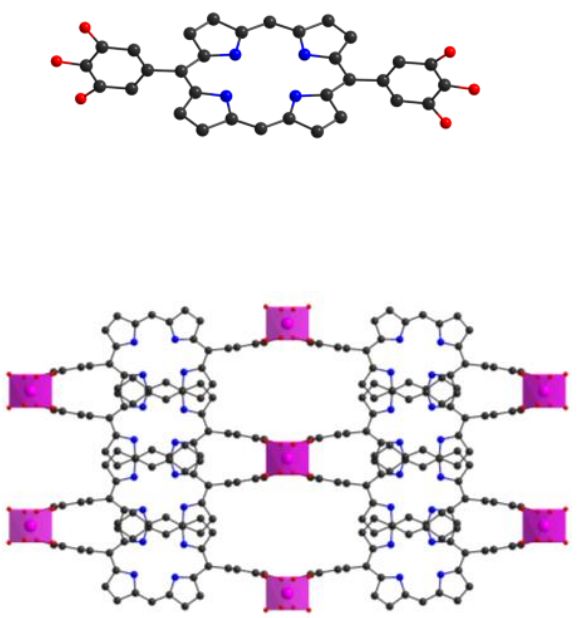

Figure 9: rod-like inorganic SBU in Zr-phenolate MOFs (a), organic ligands 5,10,15,20-tetrakis(3,4,5-trihydroxyphenyl)porphyrin (b) and (5,15-di(3,4,5trihydroxyphenyl)porphyrin) (c), structural views of MIL-173(Zr) (d and e) and Zr-DGalPP (f). Atomic colour code C (black), N(blue), O (red), Zr (magenta). 

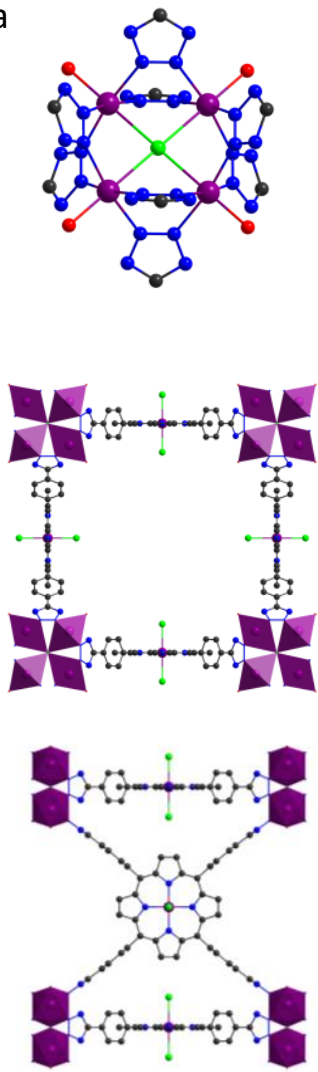

b
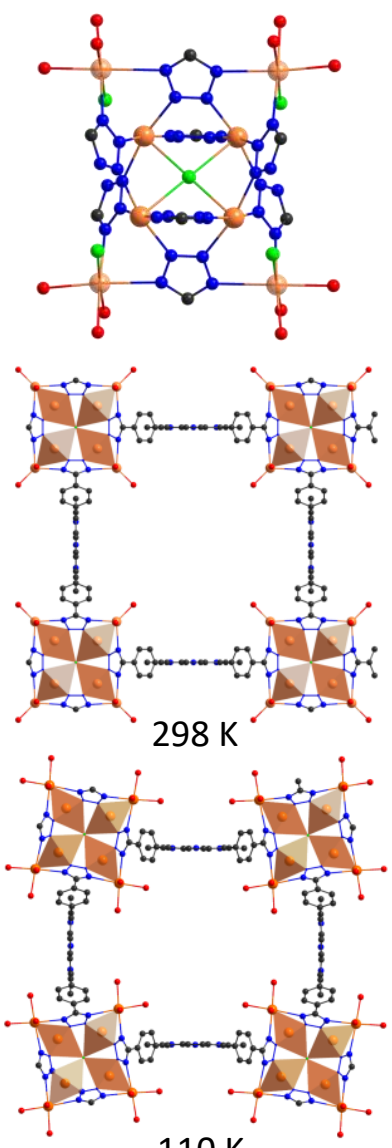

$110 \mathrm{~K}$

Figure 10: (a) inorganic SBU (top) and structural views of UTSA-57 (bottom), (b) inorganic SBU (top) and structural views (bottom) at 298 and $110 \mathrm{~K}$ for $\mathrm{PCN}-526$, showing the partially occupied Cd positions in transparent colour. Atomic colour code $\mathrm{C}$ (black), $\mathrm{N}$ (blue), $\mathrm{O}$ (red) $\mathrm{Cl}$ (green) $\mathrm{Mn}$ (violet), $\mathrm{Cd}$ (brick).

metals inserted in the porphyrinic core ${ }^{114}$. This study demonstrated that extending the ligand does not affect the non-linear optical (NLO) properties, but the metalation showed noticeable impact as the limiting effect was improved in case of ZrPP-1-Co and ZrPP-1-Mn.

Interesting variation on the structure packing was achieved through synthesis of a porphyrin bearing only two gallol units $\left(5,15-d i\left(3,4,5\right.\right.$-trihydroxyphenyl)porphyrin or DGalPP) ${ }^{115}$ (Figure 9c). Given the symmetry change on the linker, the resulting $\mathrm{Zr}$-based MOF displays a different network although based on the same inorganic SBU as evidenced from PXRD structure determination (Figure $9 \mathrm{f}$ ). In this solid the porphyrins are arranged in a staggered manner along one axis, allowing closer $\pi-\pi$ contacts between two adjacent macrocycles (intermolecular distance ca. $3.65 \AA$ ). This ladder-type arrangement leads to the mis-alignment of the porphyrins lying in parallel manner, giving the so -called $\mathrm{J}$ aggregation, as opposed to $\mathrm{H}$-aggregation fashion where parallel conjugated molecules are aligned on top of each other. This framework displays smaller pores to the previous material ( $5 \AA$ pore size from structural model) and moderate permanent porosity with a BET SA of $312 \mathrm{~m}^{2} \mathrm{~g}^{-1}$. It is well established that the aggregation mode impacts the absorption and emission properties of the material as compared to the monomeric species. The ability to control the aggregation of porphyrinic units inside the two MOFs prompted photophysical investigations and comparison of activity for the photoinduced reactive oxygen species (ROS) generation. The compound with J-aggregation mode exhibits superior activity for ROS generation and higher catalytic activity for photo-oxidation of sulfides into sulfoxides.

\section{Nitrogen donor ligands}

Among anionic nitrogen-donor ligands (pyridyl function is not considered here), porphyrinic azolates generate several kinds of MOF structures, and only one example of ortho-phenylenediamine phthalocyanine based material is reported (see above). Clearly, azolate-based frameworks attracted high attention in MOF chemistry and a valuable 
review article is available on this topic. ${ }^{116}$ Azoles are $\mathrm{sp}^{2}$ hybridized $\mathrm{N}$-donor aromatic ligands with strong and directional coordination behavior towards metal centers that makes them important building blocks not only in coordination and MOF chemistry but also in a large number of metalloenzymes. Among the five well known azoles (imidazole (Him), pyrazole (Hpyz), 1,2,4-triazole ( $\mathrm{Htz})$, 1,2,3-triazole (Hvtz), and tetrazole (Httz)), only tetrazole and pyrazole functionalized porphyrins were reported to form open framework structures. Besides, a MOF with imidazole-bearing porphyrin has been reported but it is based on mixed ligands and will not be discussed in this review $^{117}$. The pKa of azole/azolate pairs are governed by the number of $\mathrm{N}$ atoms present in the ring and the reported values for imidazole, pyrazole, and tetrazole amount to 14.5, 14.2, and 4.9 respectively. ${ }^{118}$ The basicity of azolates provides an indication about the strength of covalent bond formed with a metal, thus their greater basicity compared to aromatic carboxylates ( $\mathrm{pKa} \sim 4.2$ ) can lead to better thermal and chemical stabilities for a given cation. Based on the hard and soft acids and bases (HSAB) theory, it appears consistent that most of azolate MOFs structures are based on rather soft divalent cations, when harder trivalent and tetravalent metal ions tend to display oxophilicity. Following the same reasoning, metal-azolates are less prone to hydrolysis which is an asset in terms of chemical stability.

Imidazolate-based MOFs are probably the most well documented as they include ZIFs where metal centers are coordinated in tetrahedral geometry, but in our topic, pyrazolate and tetrazolates are the only ligands that will be considered. Similar to imidazolate, pyrazolate is a bridging bidentate ligand but here $\mathrm{N}$-atoms possess a small bridging angle (ca. $70^{\circ}$ vs. $145^{\circ}$ for imidazolate) which somehow restricts the distance between two bridged metal centers. As a consequence, unlike imidazolate, pyrazolate easily lead to the formation of polymetallic SBU. Regarding tetrazolates, the 4 consecutive $\mathrm{N}$ atoms offer greater coordination versatility therefore all coordination modes observed for all other types of azolates are accessible, ${ }^{119-125}$ but their low basicity leads to weaker coordination bond strength and reduced stability for the resulting MOFs.

Briefly, in terms of coordination modes, these azolates are well known to form SBUs similar to the ones encountered in carboxylate-based MOFs. These include chain-like metallic arrangements such as the vertex sharing $\mathrm{M}_{2}(\mathrm{pyz})_{2}$ units, ${ }^{126-129}$ equivalents of 8-connected $\mathrm{M}_{4} \mathrm{Cl}(\mathrm{RCOO})_{8}$ cluster ${ }^{130}$ and $\mathrm{M}_{4} \mathrm{O}(\mathrm{RCOO})_{8}$ cluster, ${ }^{131}$ have been reported for pyrazolates, ${ }^{132}$ and tetrazolates. ${ }^{133}$ Other divalent metal clusters are reported for tetrazolates as for example the 3connected trinuclear $\mu^{3}$-oxo-bridged cluster $\left.\left[\mathrm{M}_{3} \mathrm{O}(\mathrm{ttz})_{3}\right]\right),{ }^{134}$ trinuclear 6 -connected linear cluster $\left[\mathrm{M}_{3}\left(\mathrm{ttz}_{6}\right]_{1}, 120,121\right.$ 8connected $\mu^{4}$-chloro-bridged tetranuclear cluster $\left[\mathrm{M}_{4} \mathrm{Cl}(\mathrm{ttz})_{8}\right]^{121,124}$ and pentanuclear 8-connected oxo-bridged cluster $\left[\mathrm{M}_{5} \mathrm{O}_{2}(\mathrm{ttz})_{8}\right] .{ }^{135}$ Dissimilarities with carboxylates are also noticeable, unlike $\mathrm{O}$, each $\mathrm{N}$ in an azolate usually coordinates to only one metal center, and most of structures are based on low coordination number divalent transition metals, coordination assemblies with early transition or rare earth metal ions are very scarce. Moreover, their higher reactivity often results in fast precipitation of poorly crystalline powders, which is somehow a trade-off to achieve higher stability networks.

\section{Tetrazolates}

Tetrazolate-based porphyrinic MOFs are generally prepared in organic solvents such as DMF or DMF mixtures with $\mathrm{MeOH}$ or water, and an addition of small amount of acid is sometimes useful ${ }^{136-140}$.

The first example was reported by Guo et al. ${ }^{136}$ They reacted metallated porphyin ligand, Mn(III)Cl-TTzPP, with Mn(II) salt to isolate $\left\{\mathrm{Mn}^{\prime \prime}{ }_{0.5}\left[\mathrm{Mn}_{4}{ }_{4} \mathrm{Cl}\left(\mathrm{Mn}^{\prime \prime \prime} \mathrm{ClTTzPP}\right)_{2}\left(\mathrm{H}_{2} \mathrm{O}\right)_{4}\right]\right\} \cdot 20 \mathrm{DEF} \cdot 12 \mathrm{H}_{2} \mathrm{O} \cdot 18 \mathrm{MeOH}$ (DEF: diethylformamide) or UTSA-57 in a moderate yield. Crystal structure analysis revealed that each $\mathrm{Mn}(\mathrm{II})$ site in the $\mathrm{Mn}_{4} \mathrm{Cl}(\mathrm{ttz})_{8}-\left(\mathrm{H}_{2} \mathrm{O}\right)_{4}$ cluster features an octahedral geometry with four coplannar $\mathrm{N}$ atoms and axially occupied $\mathrm{Cl}$ and $\mathrm{O}$ atom (Figure 10 a). Here, $\mathrm{Mn}(\mathrm{III}) \mathrm{CITTZPP}$ unit acts as a four-connecting node and $\left[\mathrm{Mn}_{4} \mathrm{Cl}\right]^{7+}$ cluster as eight connecting node. Thus, four clusters are bridged by one porphyrin, generating cubic cages with a porphyrin on each face and metal clusters on the edges of the cube. The overall structure exhibits a 4, 8-connected binodal net with scu topology and the charge of the anionic framework is balanced by isolated $\mathrm{Mn}(\mathrm{II})$ ions. UTSA-57 showed thermal stability up to $400{ }^{\circ} \mathrm{C}$ and selective gas adsorption behavior (best selectivities were obtained for $\mathrm{C}_{2} \mathrm{H}_{2} / \mathrm{CH}_{4}$ mixtures). ${ }^{136}$

Shortly after, Zhou and coworkers used the free base porphyrin ( $\left.\mathrm{H}_{6} \mathrm{TTzPP}\right)$ with divalent $\mathrm{Cd}$ and $\mathrm{Mn}$ chlorides to prepare Cd-based MOFs (PCN-526 and PCN-527) and Mn-based PCN-528. ${ }^{137}$ Using a lower synthesis temperature allowed the isolation of the MOF without metal insertion in the porphyrin core $\left(\mathrm{PCN}-527,65^{\circ} \mathrm{C}\right)$ when at higher temperatures the metal reacts both with the tetrazoles and pyrrolic functions (PCN-526 and PCN-528, $130{ }^{\circ} \mathrm{C}$ ).

Like UTSA-57, PCN-526 shows a scu topology where each $\left[\mathrm{M}_{4} \mathrm{Cl}\right]^{7+}$ cluster is linked to eight porphyrins within the 3D anionic network. The charge is balanced by some well-defined partially occupied $\mathrm{Cd}$ (II) sites that interact with the two uncoordinated $\mathrm{N}$ atoms from tetrazolate groups (Figure $10 \mathrm{~b}$ ). The $\mathrm{Cd}(\mathrm{II})$ sites in the $\left[\mathrm{Cd}_{4} \mathrm{Cl}\right]^{7+}$ clusters exhibits octahedral geometry with four coplannar $\mathrm{N}$ atoms and two axially occupied $\mathrm{Cl}$ atoms. The partially occupied $\mathrm{Cd}$ (II) sites are penta-coordinated (two $\mathrm{N}$ atoms from tetrazolate groups, one $\mathrm{Cl}$ and two $\mathrm{O}$ atoms). Interestingly, upon abrupt cooling PCN-526 and PCN-527 undergoe a temperature dependent single crystal to single crystal reversible phase transition resulting in a modification of the $1 \mathrm{D}$ channels from square to relatively smaller rectangular shape. 
The phase change originates from the rotation of inorganic clusters and induces a change in the pore geometry. $X-$ ray analysis revealed that at $110 \mathrm{~K}$, all the tetrazole phenyl moieties exhibit a deviation from the original perpendicular position of the porphyrin core which results shortening in the Cd"-N length and triggers the distortion (Figure 10b). PCN-528, the Mn(II) analogue does not display partially occupied extra-fraemework Mn(II) sites and unlike the $\mathrm{Cd}$-based MOFs, does not show reversible phase change upon cooling. The phase trabsition properties were used in PCN-526 for photoluminescence tuning at variable temperatures upon encapsulation of aromatic molecules. TG analysis revealed that decomposition of PCN-526 MOF framework occurred above $250{ }^{\circ} \mathrm{C}$. In 2016 , Zhou and coworkers reported $\mathrm{Fe}(\mathrm{II})$ analogue of PCN-527. The material was obtained via post-synthetic metal exchange of PCN-527 with Fe(II) chloride. ${ }^{141}$ PCN-527-Fe displayed efficient heterogenous catalytic activity towards deacetalization-Knoevenagel condensation reaction which is associated to the greater Lewis acidity of Fe(II) compared to $\mathrm{Cd}(\mathrm{II})$.

A different topology framework was described by our group, based on mixed valent Fe II/III ions arranged in a chain $\mathrm{SBU}$ made of corner sharing $\mathrm{FeN}_{4} \mathrm{O}_{2}$ octahedra with nitrogen atoms from four different TTzPP and bridging DMF or $\mathrm{OH}$ (Figure 11a) generating an overall fry framework topology (Figures $11 \mathrm{~b}$ and c). ${ }^{138}$ Two isotopic compounds were synthesised from $\mathrm{H}_{6} \mathrm{TTzPP}, \mathrm{FeCl}_{3} .6 \mathrm{H} 2 \mathrm{O}$ and either pyrazine $(\mathrm{pz})$ or DABCO giving the respective formulas:

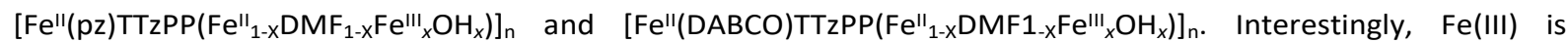
partially reduced to $\mathrm{Fe}(\mathrm{II})$ during the synthesis course probably by DMF molecules. This way two types of Fe(II) sites appear in the structure: first one is coordinated by the porphyrin core and 2 pyrazine or DABCO molecules, leading to an octahedral $\mathrm{N}_{6}$ coordination environment, the second one is part of the inorganic SBU (Figure 11). In this structure, porphyrins are stacked above each other, bridged by the heterocyclic base with the intercore distance of ca. $6.8 \AA$. Hence this study highlights that the coordination by a relatively soft Lewis base promotes Fe(II) redox state, if compared with $\mathrm{Fe}(\mathrm{III})$ carboxylate frameworks with similar topologies ${ }^{142}$. Both compounds are microporous with BET surface areas of $750 \mathrm{~m}^{2} \mathrm{~g}^{-1}$ and $510 \mathrm{~m}^{2} \mathrm{~g}^{-1}$ respectively for pyrazine and DABCO containing MOFs. ${ }^{138}$ Given the mixed valency of the framework, the stability in air is very limited as Fe(II) tends to be oxidized to Fe(III). 
a

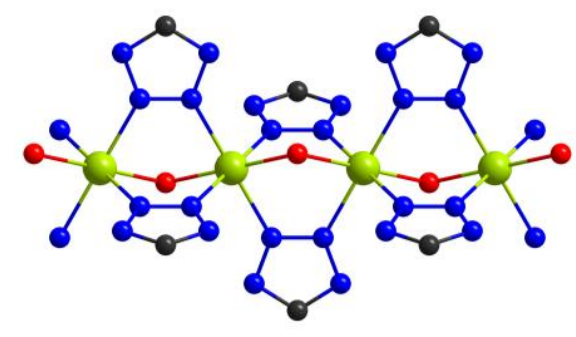

b

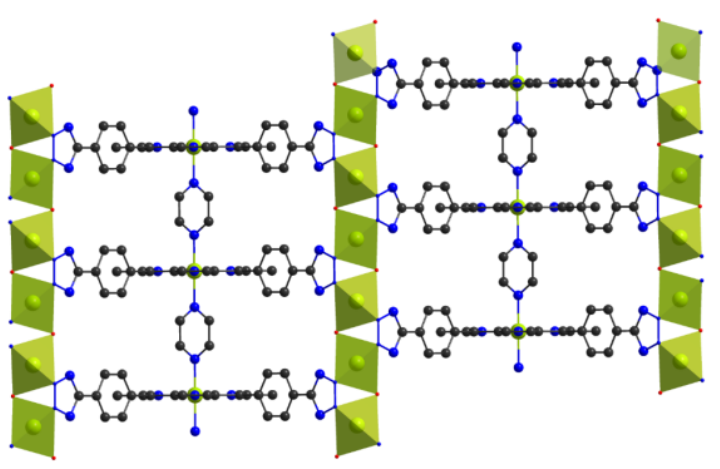

C

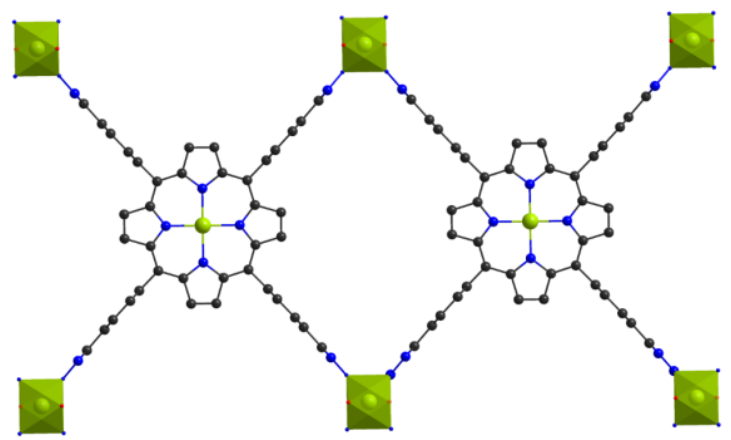

Figure 11: rod-like inorganic $\mathrm{SBU}$ of corner sharing $\mathrm{Fe}(\mathrm{Tz})_{4} \mathrm{O}_{2}$ units (a) and structural views of [Fe" pzTTzPP(Fe" $\left.\left.{ }_{1-x D M F 1-X F e}{ }^{\prime \prime}{ }_{x} O H_{x}\right)\right]_{n}$ along a axis (b) and $\mathrm{c}$ axis (c). Atomic colour code C (black), N(blue), O (red), Fe (olive). a

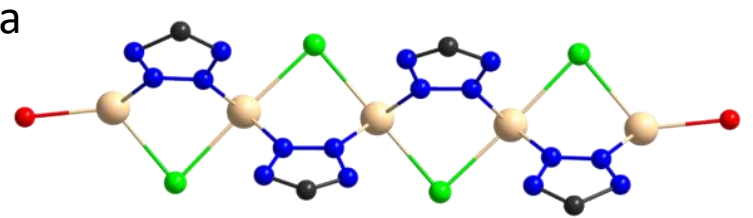

b

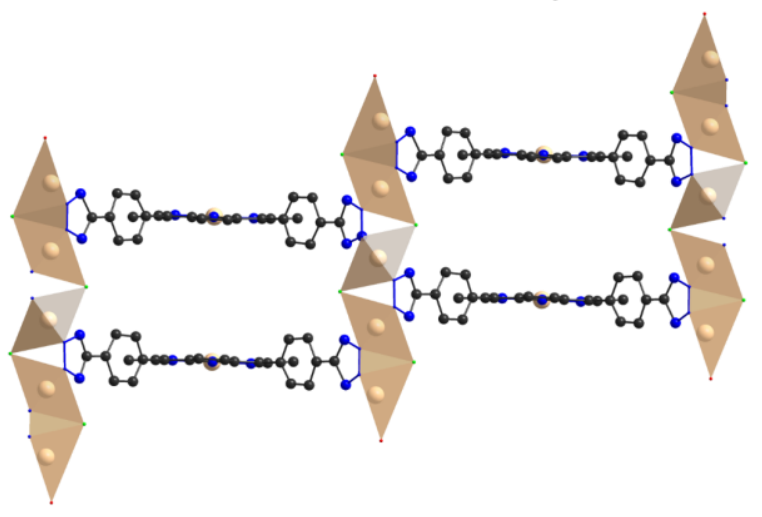

C

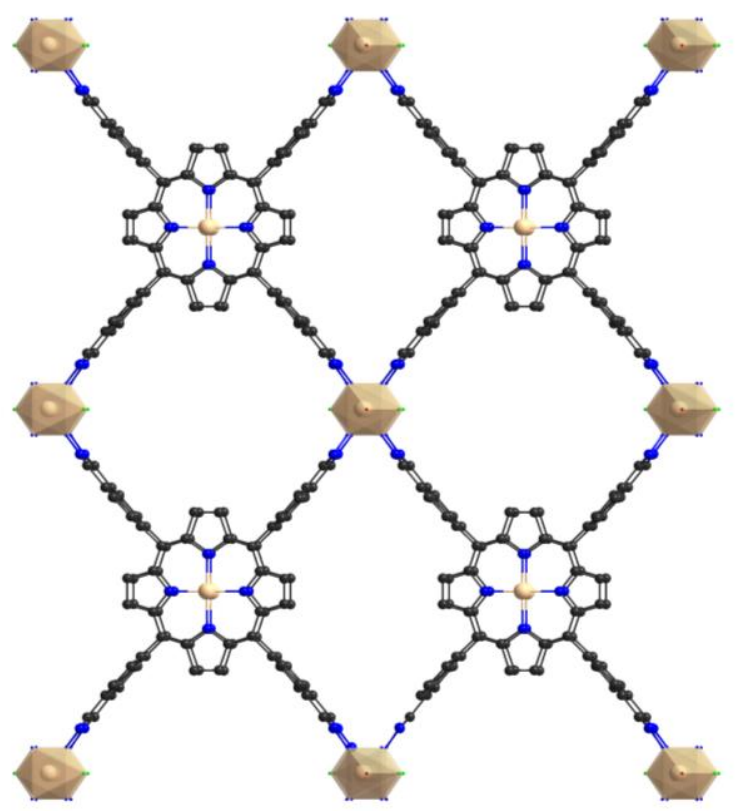

Figure 12: [Cus] cluster in LIFM-WZ-3 MOF (a), (b) structural view LIFM-WZ-3 MOF along a axis, and along $c$ axis (c), charge balancing ions are omitted for clarity. Atomic colour code C (black), N(blue), O (red), Cl (green) Cu (beige).

Another coordination arrangement was reported in 2018 by Wang and coworkers with a $\mathrm{Cu}_{5}$-cluster based 3D anionic MOF, LIFM-WZ-3 presenting a frl topology. 139 During the MOF synthesis $\mathrm{Cu}$ is incorporated in the porphyrin core where it presents a square planar geometry, and the inorganic SBU is made up from of five aligned $\mathrm{Cu}$ atoms in two kinds of environments. The three central $\mathrm{Cu}$ are corner-sharing octahedra, similar to $\mathrm{Fe}$ in the example above, coordinated by four different TTzPP in one plane and by 2 bridging $\mathrm{Cl}$ ions when the two outer $\mathrm{Cu}$ are tetrahedral, coordinated to two TTzPP, a bridging $\mathrm{Cl}$ and a $\mathrm{H}_{2} \mathrm{O}$ (Figure 12a). Water molecules are providing the 3D connectivity by linking coordination layers of stacked porphyrins. This 3-D MOF is interpenetrated with a second framework of disordered $\mathrm{H}$-bonded layers of metalloporphyrins and the charge is balanced by dimethylammonium ions (Figures $12 \mathrm{~b}$ and $\mathrm{c}$. The framework is microporous with a BET SA of $509 \mathrm{~m}^{2} \mathrm{~g}^{-1}$ and is reported stable in aqueous acid $(\mathrm{HCl}$, $\mathrm{HNO}_{3}, \mathrm{H}_{2} \mathrm{SO}_{4}$ and glacial acetic acid), base ( $\mathrm{NaOH} ; \mathrm{pH} 1$ to 9$)$ and various organic solvents. It was studied for selective adsorption and separation abilities of $\mathrm{CO}_{2} / \mathrm{CH}_{4}, \mathrm{CO}_{2} / \mathrm{N}_{2}, \mathrm{C}_{3} \mathrm{H}_{6} / \mathrm{CH}_{4}, \mathrm{C}_{2} \mathrm{H}_{6} / \mathrm{CH}_{4}$, and $\mathrm{C}_{2} \mathrm{H}_{4} / \mathrm{CH}_{4}$ at room temperature. ${ }^{139}$ One last example was proposed theoretically by Zhang et al.. It is built by combining the well-known inorganic $\mathrm{Zr}_{6} \mathrm{O}_{8}$ cuboctahedron and TTzPP, with the aim at designing structures for $\mathrm{CO}_{2}$ capture and separation at room temperature. ${ }^{143}$ Nevertheless, considering the very oxophilic character of $\operatorname{Zr}(\mathrm{IV})$, the experimental preparation of such a MOF is questionable. 


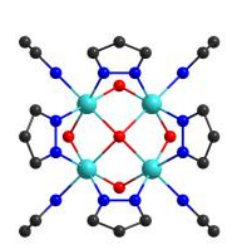

[100]

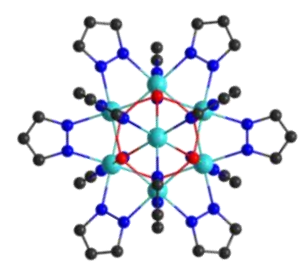

[111] b

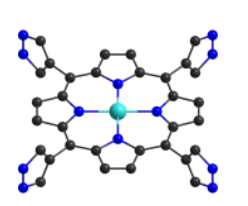

$\mathrm{Ni}-\mathrm{TPz} \mathrm{P}$

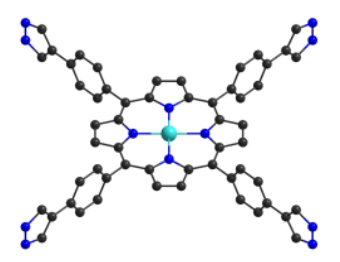

$\mathrm{Ni}-\mathrm{TPz} P \mathrm{P}$

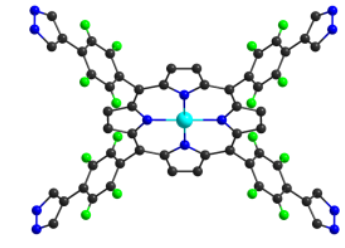

Ni-TFPzPP
C

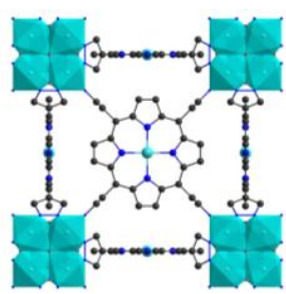

[100] d

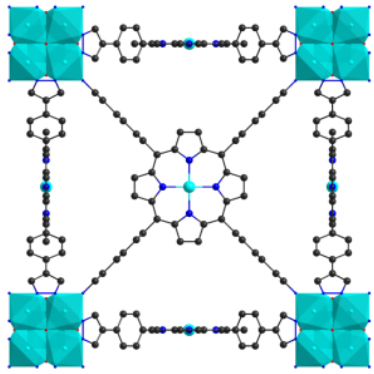

[100]

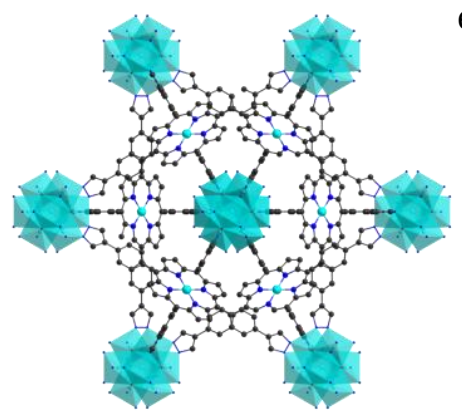

[111]

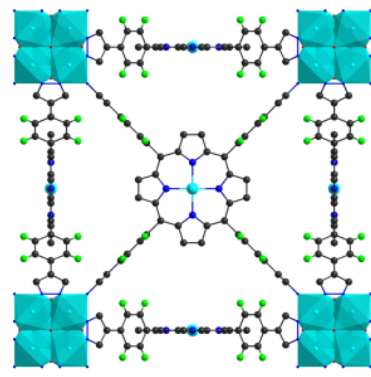

[100]

Figure 13: Nis cluster SBU in PCN-601, PCN-602 and PCN-624 along [100] and [111] directions (a), three pyrazolate porphyrinic linkers (b), structural view of PCN-601(c), PCN-602 (d) and PCN-624 (e). Atomic colour code C (black), N(blue), O (red), F (green), Ni (cyan).

\section{Pyrazolates}

Pyrazolate- porphyrin based MOFs are typically prepared under solvothermal conditions ( 75 to $130{ }^{\circ} \mathrm{C}$ ) using pure DMF or DMF-water mixture as solvent. The resulting structures present much less diversity for now, as only one kind of inorganic SBU and topology $(f t w-a)$ is reported. This fact is certainly due to the higher reactivity of pyrazoles compared to tetrazoles that is harmful for obtaining well crystallized compounds.

Zhou and coworkers developped three pyrazolate-porphyrin based porous frameworks (PCN-601, PCN-602 and $\mathrm{PCN}-624)$ with remarkable chemical stability. ${ }^{144-146} \mathrm{Here}$, combination of soft Lewis acidic [ $\mathrm{Ni}_{8}$ ] cluster and soft Lewis basic pyrazolate-porphyrin ligand was evidenced. The inorganic $\mathrm{SBU}$ is formulated as $\left[\mathrm{Ni}_{8}(\mathrm{OH})_{4}\left(\mathrm{H}_{2} \mathrm{O}\right)_{2}(\mathrm{Pz})_{12}\right](\mathrm{Pz}=$ pyrazole) and consists of $\mathrm{Ni}_{8}$ cubes where each metal is in octahedral geometry, connected to three $\mathrm{N}$ from three different porphyrins and $3 \mu_{4}-\mathrm{O}$ that link $\mathrm{Ni}$ ions on each face of the cube (Figure 13a). Each pyrazole is linked to 2 edge-sharing $\mathrm{Ni}$ and each porphyrin is therefore connected to $8 \mathrm{Ni}$ sites resulting in a 3D porous ftw- $a$ topology network with cubic cages.

In all three examples $\mathrm{Ni}$ is also inserted inside the porphryin core during the MOF formation where and lies in square planar geometry. The pore size and surface chemistry could be tuned by isotopic and isoreticular synthesis approaches. First PCN-601 was achieved with tetra-pyrazolate porphyrin TPzP (5,10,15,20-tetra(1H-pyrazol-4$\mathrm{yl}$ )porphyrin, Figure $13 \mathrm{~b}$ ) that presented rather small pores ( 2.1 $8.0 \AA$, see Figure $13 \mathrm{c})$ and a BET SA of $1309 \mathrm{~m}^{2}$ $\mathrm{g}^{-1}$ making it difficult for catalysis application in terms of diffusion limitations. ${ }^{144}$ Therefore, the linker was extended to phenyl pyrazolate TPzPP (5,10,15,20-tetrakis(4-(pyrazolate-4-yl)phenyl)porphyrin), in PCN-602 increasing the pore size to $\sim 6 \times 14 \AA$ and the BET SA to $2219 \mathrm{~m}^{2} \mathrm{~g}^{-1}$ (Figures $13 \mathrm{~b}$ and d). ${ }^{145}$ An isostructural MOF with Mn(III)porphyrin ligand is achieved when the free base porphyrin is replaced by the Mn-porphyrin during the MOF synthesis step, leading to PCN-602(Mn). This compound showed catalytic performance as a heterogeneous catalyst in the halogenation of inert hydrocarbons under alkaline conditions. Finally, the isoreticular perfluorophenyl version PCN624 was obtained by using TFPzPP linker (TFPzPP = 5,10,1(,20-tetrakis(2,3,5,6-tetrafluoro-4-(1H-pyrazol-4$\mathrm{yl}$ )phenyl))-porphyrin) with a BET SA of $2010 \mathrm{~m}^{2} \mathrm{~g}^{-1}$, the fluorine rich pores led to efficient binding ability to electronpoor fullerene derivatives and selective synthesis of fullerene-anthracene bisadduct. ${ }^{146}$. The series of the pyrazolate frameworks shows remarkable chemical stability; PCN-601 was proved to be stable to bases and acids ( $1.4 \mathrm{mg}$ of MOF mL $\mathrm{m}^{-1}$ in saturated $\mathrm{NaOH}$ at $100{ }^{\circ} \mathrm{C}$ and in $0.1 \mathrm{mM} \mathrm{HCl}$ at room temperature for $24 \mathrm{~h}$ ), $\mathrm{PCN}-602$ is reported to be stable in basic and acidic solutions $\left(2.8 \mathrm{mg} \mathrm{mL}^{-1}\right.$ in $1 \mathrm{M} \mathrm{NaOH}$ and $0.1 \mathrm{mM} \mathrm{HCl}$ at room temperature for $\left.24 \mathrm{~h}\right)$ as well as in $1 \mathrm{M}$ aqueous solutions of highly coordinating ions like fluoride, carbonate and phosphates $\left(\mathrm{KF}, \mathrm{Na}_{2} \mathrm{CO}_{3} \mathrm{and}\right.$ 
$\mathrm{K}_{3} \mathrm{PO}_{4}$ ) at room temperature for $24 \mathrm{~h}$. The improved chemical stability of PCN-624 in acidic aqueous solution (10 mg $\mathrm{mL}^{-1}$ in $1 \mathrm{M} \mathrm{HCl}$ at room temperature for $24 \mathrm{~h}$ ), compared to PCN-602, was attributed to the hydrophobic nature of the perfluorophenylene rings. PCN-624 also showcased enhanced chemical stability in the aqueous solution of coordinating anions ( $10 \mathrm{mg} \mathrm{mL}^{-1}$ in $3 \mathrm{M} \mathrm{Na}_{2} \mathrm{CO}_{3}$ and $\mathrm{K}_{3} \mathrm{PO}_{4}$ at room temperature for $24 \mathrm{~h}$ ). Differences are observed for thermal stabilities in air (from TGA data): $280^{\circ} \mathrm{C}, 300^{\circ} \mathrm{C}$ and $400^{\circ} \mathrm{C}$ for PCN-602, PCN-601 and PCN-624 respectively.

\section{Nets and relationships between crystal structures}

Although the afore-described solids present a large variety of crystal structures, most of the porous ones, especially those presenting a certain level of modularity (in term of chemical composition, metalation of the macrocycle or easiness to produce isoreticular solids), belong to a limited number of topologies, which are also sometimes known with carboxylate porphyrinic ligands. This offers a unique opportunity, for a given structural arrangement, to fine tune the structural parameters (e.g. inter-porphyrinic distances, pore size) while maintaining the shape of the pores, and thus evaluate the effect of such subtle modification on their properties (in the field of catalysis, charge transport...).

In almost all these nets, porphyrins are acting as square planar 4-connected nodes, which are combined with either molecular or rod like inorganic SBUs. As highlighted by Wang et al., the combination of such 4-connected nodes with molecular secondary buildings units gives rise to a specific set of nets, which depend on the connectivity of the inorganic SBU ${ }^{144}$.

First, if one considers the combination of tetrapyrazolate porphyrins with the 12 -connected node $\mathrm{Ni}_{8}(\mathrm{OH})_{4}\left(\mathrm{H}_{2} \mathrm{O}\right)_{8}(\mathrm{Pz}-$ $\mathrm{R})_{12}$ that gives rise to a ftw-a network (Table 1) ${ }^{144-146}$. This net was previously identified in the porphyrin tetracarboxylate MOFs built up from the $\mathrm{Zr}_{6} \mathrm{O}_{4}(\mathrm{OH})_{4}\left(\mathrm{O}_{2} \mathrm{C}-\mathrm{R}\right)_{12}$ oxocluster node in MOF-525 $5^{147}$ as well as in longer analogues (PCN-228/PCN-230148).

The combination of 8-connected nodes with square planar motifs is known to afford at least three different nets ( $c s q-a, s c u-a, s q c-a)$ depending on the symmetry of the inorganic building unit (see Table 1). While both the csq-a and $s q c-a$ ones have been obtained with various porphyrin tetracarboxylate ligands, metallated or not, and again $\mathrm{Zr}_{6}$ oxoclusters (MOF-545 $147 / \mathrm{PCN}-222^{149}$ and $\mathrm{PCN}-225^{150}$ respectively), only an interpenetrated version of the $s c u-a$ one was reported so far (NUPF-1) ${ }^{151}$. It was nevertheless the only net which was obtained upon combining a noncarboxylate porphyrin (namely TTzPP) and a 8-connected inorganic SBU $\left(\mathrm{M}_{4} \mathrm{Cl}(\mathrm{Tz})_{8}, \mathrm{M}=\mathrm{Mn}, \mathrm{Cd}\right) .{ }^{136,137} \mathrm{The}$ rationalization of this observation is clearly not obvious, and the other nets should a priori be also available with azolate porphyrins. As observed for carboxylate porphyrin, subtle synthetic modifications ${ }^{152}$ can drive the formation of one net vs. the other. 
The combination of molecular inorganic SBUs and porphyrin/phthalocyanine derivatives also leads to topologies solely observed with non-carboxylate ligands up to now. As an example, the combination of a 8-connected $\mathrm{Ni}$ (II) dimer with the tetraphosphonate porphyrin leads to a flu net in CAU-2942 (Table 1), although this topology is usually

Table 1: nets topologies and structural information for porphyrin/phthalocyanine derived MOFs based on molecular inorganic SBUs ( $\mathrm{n}$. a.: not available, *: interpenetrated)

\begin{tabular}{|c|c|c|c|}
\hline connectivity & 12-connected & 8-connected & 6-connected \\
\hline \multicolumn{4}{|l|}{$\begin{array}{l}\text { illustration of } \\
\text { inorganic SBU }\end{array}$} \\
\hline net topology & $f t w-a$ & scu-a & $\sqrt{\sqrt{1 / \sqrt{1}}}$ \\
\hline $\begin{array}{l}\text { shortest inter- } \\
\text { macrocycle distance }\end{array}$ & $\begin{array}{l}\text { perpendicular } \\
\text { / 10.9-15.2 }\end{array}$ & $\begin{array}{l}\text { perpendicular } \\
\text { / 14.1-21.9 } \AA\end{array}$ & $\begin{array}{l}\text { perpendicular } \\
\text { / } 10.5 \AA\end{array}$ \\
\hline structures & $\begin{array}{ll}\text { pyrazolate: } & \text { carboxylate: } \\
\text { PCN-601 } & \text { MOF-525 } \\
\text { PCN-602 } & \text { MOF-536 } \\
\text { PCN-624 } & \text { PCN-228 } \\
& \text { PCN-230 }\end{array}$ & 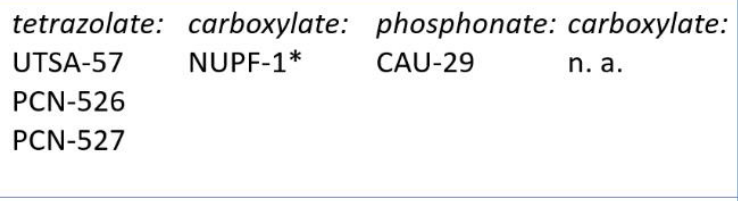 & $\begin{array}{l}\text { catecholate: carboxylate: } \\
\text { MOF-1992 n. a. }\end{array}$ \\
\hline references & $\begin{array}{ll}144- & 147 \\
146 & 148\end{array}$ & $\begin{array}{lll}136 & 151 & 42 \\
137 & \end{array}$ & 19 \\
\hline
\end{tabular}




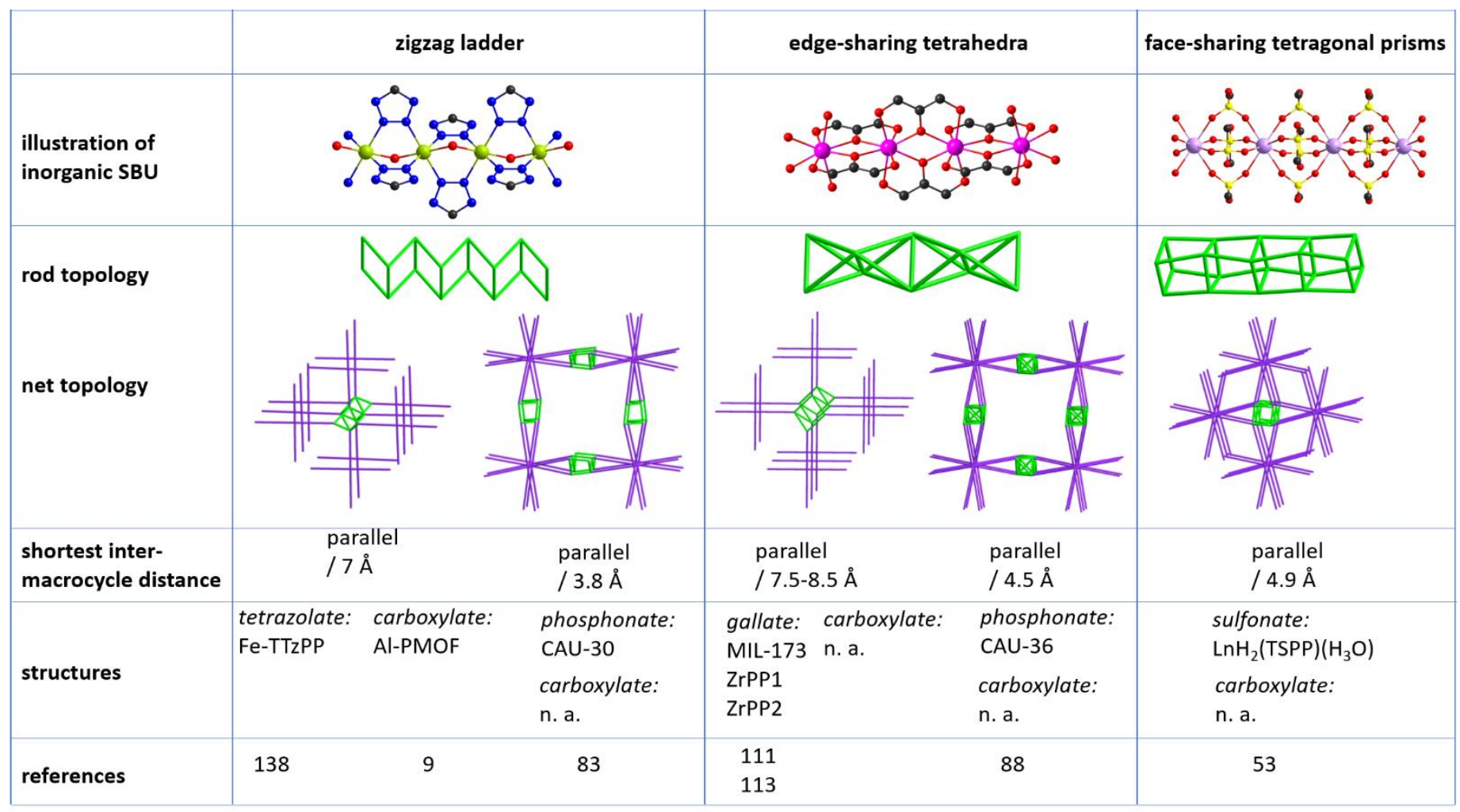

observed with tetrahedral ligands ${ }^{153}$. Eventually, 6-connected Fe(III) trimer combined with the tetracatecholate phthalocyanine afforded the roc topology for the first time. ${ }^{19}$

Rod SBUs are considered with a continuous interest, not only because they give rise to alternative structures and topologies ${ }^{154}$, but also because, for a given cation and ligand, they usually afford enhanced chemical stability compared to their molecular counterpart. ${ }^{155,156}$ The classification of rod-based nets mainly depends on the connectivity and geometry of the rod; we here mainly rely on the exhaustive review by Yaghi et al. to describe these nets. ${ }^{154}$ The zig-zag ladder (see Table 2 ) is one of the most common rod SBU, it is found in numerous $M$ (III) carboxylates such as the archetypical MIL-53. Identical chains were observed in the tetracarboxylate porphyrin Al$\mathrm{PMOF}^{9}$ (as well as the $\mathrm{Fe}, \mathrm{Ga}$ and In analogues ${ }^{142,157,158}$ ); here, each porphyrin is connected to 4 rods, leading to the fry topology. As discussed earlier, the same topology was obtained with the TTzPP and Fe(III/II $)^{138}$. Whereas, to the best of our knowledge, this is the single structure type made of rod and porphyrin carboxylate reported to date, other coordinating groups often lead to rod SBUs (Table 2).

In the $\mathrm{Zr}(\mathrm{IV})$ and $\mathrm{Hf}(\mathrm{IV})$ tetraphosphonate porphyrin CAU-3083, similar zig-zag rods, although of completely different chemical nature, are observed, but this time each porphyrin is bound to 2 rods only (rather than 4 for the fry MOFs mentioned earlier), leading to different topology not referenced so far. Another type of common rod is made of edge-sharing tetrahedra ${ }^{154}$. These rods are found in the $\mathrm{Zr}(\mathrm{IV})$ and $\mathrm{Ln}$ (III) tetragallate porphyrin MIL-173, where each porphyrin bound to 4 of these motifs ${ }^{111}$. Similar rods were found in the tetraphosphonate porphyrin CAU-3688, but that time the porphyrin cores are linked to 2 rods only. To the best of our knowledge, both topologies were not referenced so far. Eventually, a last type of rod is found in the isotypic Ln(III) tetrasulfonates porphyrin $\mathrm{LnH}_{2}(\mathrm{TSPP})\left(\mathrm{H}_{3} \mathrm{O}\right)$ solids. These rods are made of face-sharing tetragonal prisms; each porphyrin bound to 4 rods, leading to a $z$ bs net. ${ }^{154}$

For each type of inorganic SBU (molecular or rod), although the topologies of the nets are different, strong structural similarities exist. In the case of molecular SBUs, whatever the nature of the net (with the exception of the flu topology), the shortest distance between porphyrins correspond to perpendicular ligands. If one considers the arrangement of the porphyrin only, the scu and roc nets appear as defective version of the ftw one, with similar shortest porphyrin-porphyrin distances, but potentially facilitated diffusion of guests within their pores. Regarding the rod-based structures, all porphyrin cores lie parallel to each other, either eclipsed (Fe-TTzPP, MIL-173) or slightly rotated (CAU-30 and CAU-36, $\mathrm{LnH}_{2}(\mathrm{TSPP})\left(\mathrm{H}_{3} \mathrm{O}\right)$ ). These structures can be divided in three categories, depending on the size of the channel running along the direction of the rod: (i) in $\mathrm{LnH}_{2}(\mathrm{TSPP})\left(\mathrm{H}_{3} \mathrm{O}\right)$, the 4-connected porphyrins together with the face-sharing tetragonal prisms based rods lead to very small channels (2-4 Å); (ii) the 4 connected 
tetrazolate and gallate porphyrins found in Fe-TTzPP and MIL-173 respectively afford channels of similar intermediate size (5-9 $\AA$ ), the difference between the structures leading to different corrugation path in the perpendicular direction; (iii) two 2-connected phosphonate porphyrins in CAU-30 and CAU-36 lead to 1-D channels of higher dimension (9-14 ̊), hence potentially facilitating the diffusion of guests (providing that the cavities could be emptied). The last example clearly shows the benefit on non-carboxylate ligands.

\section{Conclusions}

The quest for new MOFs has led to the (re-)exploration of complexing groups alternative to carboxylates in the last 10 years; this evolution has logically fed the field of porphyrin and phthalocyanine MOFs. As summarized in Table 3, 7 types of coordinating groups were used and yielded materials with a large diversity of properties that are sometimes directly linked to the nature of the coordinating function (for example, opportunities in protonic and electronic conductivities offered by phosphonates and polyphenolates respectively). The evolution in the design and synthesis of novel porphyrine/phthalocyanines based MOFs offers opportunities:

(i) Regarding the synthetic aspects, the use of highly polar and protic porphyrin and phthalocyanine derivatives (phosphonate, sulfonate, catecholate, gallate) reasonably soluble in water allows avoiding the use of toxic solvents such as DMF, hence opening the way towards greener syntheses. ${ }^{159}$

(ii) The properties of MOF structures already known with carboxylates could be modulated: for example, the use of pyrazolate derivatives allowed to achieve improved chemical stabilities.

Table 3: Summary of the porphyrin/phthalocyanine derived MOFs described in this review article (the number of topologies refers to porphyrin-based MOF without any organic co-ligands).

\begin{tabular}{|c|c|c|c|c|c|c|c|c|c|}
\hline & $\begin{array}{l}\text { pKa } \\
\text { range }\end{array}$ & $\begin{array}{l}\text { Synthesis } \\
\text { conditions }\end{array}$ & M & $\begin{array}{l}\text { number of } \\
\text { topologies }\end{array}$ & $\begin{array}{l}\text { dimensionality } \\
\text { of the SBU }\end{array}$ & $\begin{array}{c}\text { dimensionality } \\
\text { of the } \\
\text { framework }\end{array}$ & BET & $\begin{array}{l}\text { chemical } \\
\text { stability (in } \\
\text { suspension) }\end{array}$ & $\begin{array}{l}\text { properties } \\
\text { explored }\end{array}$ \\
\hline SULFONATE & negative & Aqueous media & $\operatorname{Ln}^{3+}$ & 2 & $\begin{array}{l}\text { dimers } \\
1 D\end{array}$ & $3 D$ & $\begin{array}{l}\text { no intrinsic } \\
\text { porosity }\end{array}$ & very limited & $\begin{array}{l}\text { Luminescence } \\
\text { and ROS } \\
\text { generation }\end{array}$ \\
\hline PHOSPHONATE & $\begin{array}{c}\sim 3 \text { and } \\
8\end{array}$ & Aqueous media & $\begin{array}{l}\mathrm{Na}^{+} \\
\mathrm{Cd}^{2+} \mathrm{Mn}^{2+} \mathrm{Co}^{2+} \\
\mathrm{Ni}^{2+} \\
\mathrm{Ln}^{3+} \\
\mathrm{Zr}^{4+} \mathrm{Hf}^{4+}\end{array}$ & 5 & $\begin{array}{l}\text { dimers } \\
1 D\end{array}$ & $3 D$ & up to $970 \mathrm{~m}^{2} \mathrm{~g}^{-1}$ & $\begin{array}{l}\text { high for } \\
\text { tetravalent } \\
\text { cations } \\
\text { limited for } \\
\text { lower valency }\end{array}$ & $\begin{array}{l}\text { Protonic } \\
\text { conductivity } \\
\text { Redox properties } \\
\text { Luminescence for } \\
\text { sensing and } \\
\text { catalysis }\end{array}$ \\
\hline CATECHOLATE & $9-14$ & $\begin{array}{l}\text { organic solvent } \\
\text { /water mixtures }\end{array}$ & $\begin{array}{l}\mathrm{Fe}^{2+} \mathrm{Ni}^{2+} \mathrm{Cu}^{2+} \\
\mathrm{Fe}^{3+}\end{array}$ & 2 & $\begin{array}{l}\text { trimer } \\
\text { single ion }\end{array}$ & $\begin{array}{l}3 D \\
2 D\end{array}$ & $\begin{array}{l}\text { up to } 1471 \mathrm{~m}^{2} \mathrm{~g}^{-1} \\
\text { (3D) } \\
\text { up to } 412 \mathrm{~m}^{2} \mathrm{~g}^{-1} \\
\text { (2D) }\end{array}$ & Good & $\begin{array}{l}\text { Electrocatalysis } \\
\text { Electric } \\
\text { conductivity, } \\
\text { battery cathode } \\
\text { material, sensing }\end{array}$ \\
\hline GALLATE & $9-14$ & $\begin{array}{l}\text { DMF/water } \\
\text { mixtures }\end{array}$ & $\begin{array}{l}\mathrm{Ln}^{3+} \\
\mathrm{Zr}^{4+}\end{array}$ & 2 & $1 \mathrm{D}$ & $3 \mathrm{D}$ & up to $850 \mathrm{~m}^{2} \mathrm{~g}^{-1}$ & $\begin{array}{l}\text { high }\left(\mathrm{Zr}^{4+}\right) \\
\text { low }\left(\operatorname{Ln}^{3+}\right)\end{array}$ & $\begin{array}{l}\text { Catalysis, proton } \\
\text { conductivity, NLO, } \\
\text { ROS generation }\end{array}$ \\
\hline TETRAZOLATE & $\sim 5$ & $\begin{array}{l}\text { organic solvents } \\
\text { (DMF, DMF/MeOH } \\
\text { DEF/MeOH) }\end{array}$ & $\begin{array}{l}\mathrm{Cd}^{2+} \mathrm{Mn}^{2+} \mathrm{Cu}^{2+} \\
\mathrm{Fe}^{2+} / \mathrm{Fe}^{3+}\end{array}$ & 3 & $\begin{array}{l}\text { tetramer } \\
\text { pentamer } \\
1 \mathrm{D}\end{array}$ & $\begin{array}{l}3 \mathrm{D} \\
2 \mathrm{D} \mathrm{\textrm {H } _ { 2 }} \mathrm{O} \text { bridged } \\
\text { layers }\end{array}$ & up to $750 \mathrm{~m}^{2} \mathrm{~g}^{-1}$ & Moderate & $\begin{array}{l}\text { Luminescence, } \\
\text { catalysis, gas } \\
\text { separation }\end{array}$ \\
\hline PYRAZOLATE & $\sim 14$ & $\begin{array}{l}\mathrm{DMF} \text { and } \\
\text { DMF/water } \\
\text { mixtures }\end{array}$ & $\mathrm{Ni}^{2+}$ & 1 & octamer & $3 D$ & up to $2019 \mathrm{~m}^{2} \mathrm{~g}^{-1}$ & High & $\begin{array}{l}\text { Catalysis, } \\
\text { selective } \\
\text { molecular } \\
\text { binding }\end{array}$ \\
\hline DIAMINO & $\begin{array}{l}\sim 2 \text { and } \\
4.4\end{array}$ & $\begin{array}{l}\text { DMSO/water } \\
\text { mixture }\end{array}$ & $\mathrm{Ni}^{2+}$ & 1 & single ion & $2 \mathrm{D}$ & $593 \mathrm{~m}^{2} \mathrm{~g}^{-1}$ & not reported & electrocatalysis \\
\hline
\end{tabular}

(iii) These ligands also obviously afforded new structure types, because these complexing groups can drive the formation of specific SBUs - such as rods - which can further lead to a high stability towards competitive complexing groups (gallate) and/or very large 1-D pores (phosphonate).

(iv) Few of these complexing groups (sulfonate, phosphonate, catecholate, gallate) react preferentially with hard acids (rather $\mathrm{M}(\mathrm{III} / \mathrm{IV}$ ) than $\mathrm{M}(\mathrm{II})$ cations), hence potentially facilitating the preparation of porphyrin free based MOFs, which can be easily metallated post-synthetically, broadening the scope of available materials and properties. Hence, it appears clearly that while the carboxylate group may still lead the field of porphyrin MOFs for years, other complexing groups will be considered with a growing interest. 


\section{List of Acronyms}

\begin{tabular}{|c|c|}
\hline ALD & Atomic Layer Deposition \\
\hline BET & Brunauer-Emmett-Teller \\
\hline Cat & catechol \\
\hline CAU & Christian-Albrechts-University \\
\hline CNT & Carbon Nano Tube \\
\hline DABCO & 1,4-Diazabicyclo[2.2.2]octane \\
\hline DDQ & 2,3-dichloro-5,6-dicyano-1,4-benzoquinone \\
\hline DEF & Diethylformamide \\
\hline DEZ & Diethylzinc \\
\hline DMA & Dimethylamonium \\
\hline DMF & Dimethylformamide \\
\hline DMSO & Dimethysulfoxide \\
\hline EPR & Electron Paramagnetic Resonance \\
\hline$\eta$ & hapticity \\
\hline Gal & gallol \\
\hline $\mathrm{H}_{8}$ DGalTPP & 5,15-di(3,4,5-trihydroxyphenyl)porphyrin \\
\hline HER & Hydrogen Evolution Reaction \\
\hline HSAB & Hard and Soft (Lewis) Acids and Bases \\
\hline $\mathrm{H}_{10}$ TCatPP & 5,10,15,20-tetrakis(3,4-dihydroxyphenyl)porphyrin \\
\hline $\mathrm{H}_{14}$ TGalPP & 5,10,15,20-tetrakis(3,4,5-trihydroxyphenyl)porphyrin \\
\hline $\mathrm{H}_{6} \mathrm{TPz} \mathrm{P}$ & 5,10,15,20-tetrakis(4-(2H-pyraol-4-yl))porphyrin \\
\hline $\mathrm{H}_{6} \mathrm{TTzPP}$ & 5,10,15,20-tetrakis(4-(2H-tetrazol-5 yl)phenyl)porphyrin \\
\hline IPCE & Institute of Physical Chemistry and Electrochemistry of Russian Academy of Science \\
\hline $\mathrm{MeOH}$ & Methanol \\
\hline MIL & Matériaux de l'Institut Lavoisier \\
\hline MOF & Metal Organic Framework \\
\hline MPc & metallated phthalocyanine \\
\hline$\mu$ & bridging ligand \\
\hline NiToDAPc & $2,3,9,10,16,17,23,24$-octaamino-phthalocyaninato nickel(II) \\
\hline NLO & Non Linear Optics \\
\hline NMP & n-methyl-2-pyrrolidone \\
\hline NUPF & Nanjing University Porphyrinic Framework \\
\hline OER & Oxygen Evolution Reaction \\
\hline Pc & Phthalocyanine \\
\hline PCN & Porous Coordination Network \\
\hline PSM & Post-Synthesis Modification \\
\hline PXRD & Powder X-ray Diffraction \\
\hline $\mathrm{pz}$ & pyrazine \\
\hline RHE & reversible hydrogen electrode \\
\hline ROS & Reactive Oxygen Species \\
\hline SA & Surface Area \\
\hline SBU & Secondary Building Unit \\
\hline TCatPc & $(2,3,9,10,16,17,23,24$-octahydroxy)phthalocyanine \\
\hline TCPP & tetrakis(4-carboxyphenyl)porphyrin \\
\hline TFA & Trifluoroacetic Acid \\
\hline TGA & Thermogravimetric Analysis \\
\hline TMA & Trimethylaluminium \\
\hline TmPPP & tetrakis(meta-phosphonatophenyl)porphyrinate \\
\hline TPPP & tetrakis(p-phenylphosphonic acid)porphyrin \\
\hline TPzP & 5,10,15,20-tetra(1H-pyrazol-4-yl)porphyrin \\
\hline TPzPP & 5,10,15,20-tetrakis(4-(pyrazolate-4-yl)phenyl)porphyrin \\
\hline Ts & Tosyl \\
\hline TSPP & tetrakis(4-sulfonatophenyl)porphyrin \\
\hline
\end{tabular}




\section{Conflicts of interest}

There are no conflicts to declare.

\section{Acknowledgements}

The authors thank the ANR French Research Agency (project STREAM), the CNRS and the University of Lyon 1 for providing financial support for research and postdoctoral fellowship. TD thanks the region Pays de la Loire for funding (project PSR 'MatHySE2').

\section{Notes and references}

1 S. LESAGE, H. XU and L. DURHAM, Hydrol. Sci. J., 1993, 38, 343-354.

2 L. Li, S. Shen, R. Lin, Y. Bai and H. Liu, Chem. Commun., 2017, 53, 9986-9989.

3 C. F. Pereira, F. Figueira, R. F. Mendes, J. Rocha, J. T. Hupp, O. K. Farha, M. M. Q. Simões, J. P. C. Tomé and F. A. A. Paz, Inorg. Chem., 2018, 57, 3855-3864.

4 J. Zhang, J. Wang, S. Long, S. B. Peh, J. Dong, Y. Wang, A. Karmakar, Y. D. Yuan, Y. Cheng and D. Zhao, Inorg. Chem., 2018, 57, 13631-13639.

5 J. Liu, W. Zhou, J. Liu, Y. Fujimori, T. Higashino, H. Imahori, X. Jiang, J. Zhao, T. Sakurai, Y. Hattori, W. Matsuda, S. Seki, S. K. Garlapati, S. Dasgupta, E. Redel, L. Sun and C. Wöll, J. Mater. Chem. A, 2016, 4, 12739-12747.

6 E. D. Spoerke, L. J. Small, M. E. Foster, J. Wheeler, A. M. Ullman, V. Stavila, M. Rodriguez and M. D. Allendorf, J. Phys. Chem. C, 2017, 121, 4816-4824.

7 Y.-B. Tian, Y.-Y. Wang, S.-M. Chen, Z.-G. Gu and J. Zhang, ACS Appl. Mater. Interfaces, 2020, 12, 1078-1083.

8 Q. Zuo, T. Liu, C. Chen, Y. Ji, X. Gong, Y. Mai and Y. Zhou, Angew. Chem. Int. Ed., 2019, 58, 10198-10203.

9 A. Fateeva, P. A. Chater, C. P. Ireland, A. A. Tahir, Y. Z. Khimyak, P. V. Wiper, J. R. Darwent and M. J. Rosseinsky, Angew. Chem. Int. Ed., 2012, 51, 7440-7444.

10 J. A. Johnson, J. Luo, X. Zhang, Y.-S. Chen, M. D. Morton, E. Echeverría, F. E. Torres and J. Zhang, ACS Catal., 2015, 5, 5283-5291.

11 Z. W. Jiang, Y. C. Zou, T. T. Zhao, S. J. Zhen, Y. F. Li and C. Z. Huang, Angew. Chem. Int. Ed., 2020, 59, 3300-3306.

12 C. F. Pereira, Y. Liu, A. Howarth, F. Figueira, J. Rocha, J. T. Hupp, O. K. Farha, J. P. C. Tomé and F. A. Almeida Paz, ACS Appl. Nano Mater., 2019, 2, 465-469.

13 D. T. Lee, J. D. Jamir, G. W. Peterson and G. N. Parsons, Matter, 2020, 2, 404-415.

14 D. T. Lee, J. D. Jamir, G. W. Peterson and G. N. Parsons, Small, 2019, 15, 1805133.

15 O. T. Wilcox, A. Fateeva, A. P. Katsoulidis, M. W. Smith, C. A. Stone and M. J. Rosseinsky, Chem Commun, 2015, 51, 14989-14991.

16 M. Lions, J.-B. Tommasino, R. Chattot, B. Abeykoon, N. Guillou, T. Devic, A. Demessence, L. Cardenas, F. Maillard and A. Fateeva, Chem. Commun., 2017, 53, 6496-6499. 

DOI:10.1002/adfm.201901301.

18 B.-X. Dong, S.-L. Qian, F.-Y. Bu, Y.-C. Wu, L.-G. Feng, Y.-L. Teng, W.-L. Liu and Z.-W. Li, ACS Appl. ENERGY Mater., 2018, 1, 4662-4669.

19 R. Matheu, E. Gutierrez-Puebla, M. Á. Monge, C. S. Diercks, J. Kang, M. S. Prévot, X. Pei, N. Hanikel, B. Zhang, P. Yang and O. M. Yaghi, J. Am. Chem. Soc., 2019, 141, 17081-17085.

20 K. A. D. F. Castro, F. Figueira, F. A. Almeida Paz, J. P. C. Tomé, R. S. da Silva, S. Nakagaki, M. G. P. M. S. Neves, J. A. S. Cavaleiro and M. M. Q. Simões, Dalton Trans, 2019, 48, 8144-8152.

21 W. Bai, S. Li, J. Ma, W. Cao and J. Zheng, J Mater Chem A, 2019, 7, 9086-9098.

22 W. Zhao, W. Wang, J. Peng, T. Chen, B. Jin, S. Liu, W. Huang and Q. Zhao, DALTON Trans., 2019, 48, 9631-9638.

23 L. Sun, J. Xie, Z. Chen, J. Wu and L. Li, DALTON Trans., 2018, 47, 9989-9993.

24 H. Yao, F. Zhang, G. Zhang, H. Luo, L. Liu, M. Shen and Y. Yang, Chem. Eng. J., 2018, 334, 2547-2557.

25 Q. Deng, P. Sun, L. Zhang, Z. Liu, H. Wang, J. Ren and X. Qu, Adv. Funct. Mater., 2019, 29, 1903018.

26 M. He, Y. Chen, C. Tao, Q. Tian, L. An, J. Lin, Q. Tian, H. Yang and S. Yang, ACS Appl. Mater. Interfaces, 2019, 11, 41946-41956.

27 G. Lan, K. Ni, S. S. Veroneau, X. Feng, G. T. Nash, T. Luo, Z. Xu and W. Lin, J. Am. Chem. Soc., 2019, 141, 4204-4208.

28 W. Liu, Y.-M. Wang, Y.-H. Li, S.-J. Cai, X.-B. Yin, X.-W. He and Y.-K. Zhang, Small, 2017, 13, 1603459.

29 L. Gui, J. Zhou, L. Zhou and S. Wei, J Mater Chem B, 2018, 6, 2078-2088.

30 Z. Huang, L. Huang, Y. Huang, Y. He, X. Sun, X. Fu, X. Xu, G. Wei, D. Chen and C. Zhao, Nanoscale, 2017, 9, 1588315894.

31 B. F. Abrahams, B. F. Hoskins, D. M. Michail and R. Robson, Nature, 1994, 369, 727-729.

32 B. F. Abrahams, B. F. Hoskins and R. Robson, J. Am. Chem. Soc., 1991, 113, 3606-3607.

33 S. Huh, S.-J. Kim and Y. Kim, CrystEngComm, 2016, 18, 345-368.

34 Z. Guo and B. Chen, Dalton Trans., 2015, 44, 14574-14583.

35 S. A. Younis, D.-K. Lim, K.-H. Kim and A. Deep, Adv. Colloid Interface Sci., 2020, 277, 102108.

36 X. Zhang, M. C. Wasson, M. Shayan, E. K. Berdichevsky, J. Ricardo-Noordberg, Z. Singh, E. K. Papazyan, A. J. Castro, P. Marino, Z. Ajoyan, Z. Chen, T. Islamoglu, A. J. Howarth, Y. Liu, M. B. Majewski, M. J. Katz, J. E. Mondloch and O. K. Farha, Coord. Chem. Rev., 2020, 213615.

37 A. D. Adler, F. R. Longo, J. D. Finarelli, J. Goldmacher, J. Assour and L. Korsakoff, J. Org. Chem., 1967, 32, 476-476.

38 J. S. Lindsey, I. C. Schreiman, H. C. Hsu, P. C. Kearney and A. M. Marguerettaz, J. Org. Chem., 1987, 52, 827-836.

39 L. Jiang, F. Lu, H. Li, Q. Chang, Y. Li, H. Liu, S. Wang, Y. Song, G. Cui, N. Wang, X. He and D. Zhu, J. Phys. Chem. B, 2005, 109, 6311-6315.

40 G. C. Quan, M. Denis, B. Abeykoon, J.-B. Tommasino, E. Jeanneau, C. Journet, T. Devic and A. Fateeva, J. Porphyr. Phthalocyanines, 2019, 23, 103-116.

41 P. J. F. Gauuan, M. P. Trova, L. Gregor-Boros, S. B. Bocckino, J. D. Crapo and B. J. Day, Bioorg. Med. Chem., 2002, 10, 3013-3021.

42 T. Rhauderwiek, K. Wolkersdörfer, S. Øien-Ødegaard, K.-P. Lillerud, M. Wark and N. Stock, Chem. Commun., 2018, 54, 389-392.

43 P. Kubát, K. Lang and P. Anzenbacher, Biochim. Biophys. Acta BBA - Gen. Subj., 2004, 1670, 40-48.

44 A. P. Côté and G. K. H. Shimizu, 35th Int. Conf. Coord. Chem., 2003, 245, 49-64. 
S. A. Dalrymple, M. Parvez and G. K. H. Shimizu, Chem. Commun., 2001, 2672-2673.

S. A. Dalrymple and G. K. H. Shimizu, Chem. Commun., 2002, 2224-2225.

G. Zhang, G. Wei, Z. Liu, S. R. J. Oliver and H. Fei, Chem. Mater., 2016, 28, 6276-6281.

D. K. Panda, K. Maity, A. Palukoshka, F. Ibrahim and S. Saha, ACS Sustain. Chem. Eng., 2019, 7, 4619-4624.

D. Yan, S. Qin, L. Chen, J. Lu, J. Ma, M. Wei, D. G. Evans and X. Duan, Chem. Commun., 2010, 46, 8654-8656.

H. Zhong, R. Tian, X. Gong, D. Li, P. Tang, N. Alonso-Vante and Y. Feng, J. Power Sources, 2017, 361, 21-30.

M. Poß, H. Gröger and C. Feldmann, Chem. Commun., 2018, 54, 1245-1248.

J. Demel, P. Kubát, F. Millange, J. Marrot, I. Císařová and K. Lang, Inorg. Chem., 2013, 52, 2779-2786.

W.-T. Chen, Y. Yamada, G.-N. Liu, A. Kubota, T. Ichikawa, Y. Kojima, G.-C. Guo and S. Fukuzumi, Dalton Trans., 2011, 40, 12826-12831.

W. T. Chen, R. H. Hu, Z. G. Luo, H. L. Chen and J. Liu, Jiegou Huaxue, 2015, 34, 279-284.

W.-T. Chen, R.-H. Hu, H.-L. Chen, X. Zhang and H.-R. Fu, J. Iran. Chem. Soc., 2015, 12, 277-282.

Y.-P. Pei, J.-G. Huang, R.-H. Hu, Y.-X. Yang, J. Zhou and W.-T. Chen, J. Porphyr. Phthalocyanines, 2015, 19, 811-818.

W.-T. Chen, Q.-Y. Luo, Y.-P. Xu, Y.-K. Dai, S.-L. Huang and P.-Y. Guo, Inorg. Chem. Commun., 2014, 49, $16-18$.

W.-T. Chen, Z.-G. Luo, Y.-F. Wang, X. Zhang and H.-R. Fu, Inorganica Chim. Acta, 2014, 414, 1-7.

W.-T. Chen, D.-S. Liu, Y.-P. Xu, Q.-Y. Luo and Y.-P. Pei, Luminescence, 2016, 31, 158-163.

61 X. Zhang, W.-T. Cheng, T. Suenobu, S. Fukuzumi, M.-S. Wang and G.-C. Guo, J. Porphyr. Phthalocyanines, 2015, 19, $1225-1231$.

62 W.-T. Chen, R.-H. Hu, Y.-F. Wang, X. Zhang and J. Liu, J. Solid State Chem., 2014, 213, 218-223.

63 X.-G. Yi, J.-G. Huang, R.-H. Hu, Z.-G. Luo, Y.-P. Pei and W.-T. Chen, J. Porphyr. Phthalocyanines, 2015, 19, 10721079.

64 R.-H. Hu, C. Yi, Y. Li, Z.-X. Zhang, L.-Z. Lin and W.-T. Chen, J. Porphyr. Phthalocyanines, 2018, 22, 325-330.

65 W.-T. Chen, Z.-X. Zhang, L.-Z. Lin, Y. Sui, D.-S. Liu and H.-L. Chen, Cryst. Growth Des., 2018, 18, 5456-5464.

66 W.-T. Chen, J.-G. Hang, X.-Y. Lei, R.-H. Hu, Y.-P. Pei, Y.-X. Yang and J. Zhou, J. Iran. Chem. Soc., 2016, 13, 95-101.

67 Y.-P. Pei, J.-G. Huang, H.-L. Chen, H.-M. Kuang, J. Zhou, Y.-X. Yang and W.-T. Chen, J. Porphyr. Phthalocyanines, 2015, 19, 1140-1146.

68 K. D. Demadis and N. Stavgianoudaki, in Metal Phosphonate Chemistry: From Synthesis to Applications, The Royal Society of Chemistry, 2012, pp. 438-492.

69 P. Bhanja, J. Na, T. Jing, J. Lin, T. Wakihara, A. Bhaumik and Y. Yamauchi, Chem. Mater., 2019, 31, 5343-5362.

70 J. K. Zaręba, Inorg. Chem. Commun., 2017, 86, 172-186.

71 M. Taddei, F. Costantino and R. Vivani, Eur. J. Inorg. Chem., 2016, 2016, 4300-4309.

72 S.-S. Bao, G. K. H. Shimizu and L.-M. Zheng, Spec. Issue 8th Chin. Coord. Chem. Conf., 2019, 378, 577-594.

73 G. Yücesan, Y. Zorlu, M. Stricker and J. Beckmann, Coord. Chem. Rev., 2018, 369, 105-122. 
76 Y. Zorlu, D. Erbahar, A. Çetinkaya, A. Bulut, T. S. Erkal, A. O. Yazaydin, J. Beckmann and G. Yücesan, Chem. Commun., 2019, 55, 3053-3056.

77 A. Bulut, Y. Zorlu, R. Topkaya, B. Aktaş, S. Doğan, H. Kurt and G. Yücesan, Dalton Trans., 2015, 44, 12526-12529.

78 C.-Y. Gao, J. Ai, H.-R. Tian, D. Wu and Z.-M. Sun, Chem. Commun., 2017, 53, 1293-1296.

79 N. Hermer and N. Stock, Dalton Trans., 2015, 44, 3720-3723.

80 M. Maares, M. M. Ayhan, K. B. Yu, A. O. Yazaydin, K. Harmandar, H. Haase, J. Beckmann, Y. Zorlu and G. Yücesan, Chem. - Eur. J., 2019, 25, 11214-11217.

81 Y. Y. Enakieva, A. A. Sinelshchikova, M. S. Grigoriev, V. V. Chernyshev, K. A. Kovalenko, I. A. Stenina, A. B. Yaroslavtsev, Y. G. Gorbunova and A. Y. Tsivadze, Chem. - Eur. J., 2019, 25, 10552-10556.

82 Y. Y. Enakieva, A. A. Sinelshchikova, M. S. Grigoriev, V. V. Chernyshev, K. A. Kovalenko, I. A. Stenina, A. B. Yaroslavtsev, Y. G. Gorbunova and A. Yu. Tsivadze, Chem. - Eur. J., , DOI:10.1002/chem.202003893.

83 T. Rhauderwiek, H. Zhao, P. Hirschle, M. Döblinger, B. Bueken, H. Reinsch, D. De Vos, S. Wuttke, U. Kolb and N. Stock, Chem. Sci., 2018, 9, 5467-5478.

84 M. Taddei, F. Costantino and R. Vivani, Inorg. Chem., 2010, 49, 9664-9670.

85 M. Taddei, F. Costantino, F. Marmottini, A. Comotti, P. Sozzani and R. Vivani, Chem. Commun., 2014, 50, 1483114834.

86 M. Taddei, F. Costantino, R. Vivani, S. Sabatini, S.-H. Lim and S. M. Cohen, Chem. Commun., 2014, 50, 5737-5740.

87 Y. Bai, Y. Dou, L.-H. Xie, W. Rutledge, J.-R. Li and H.-C. Zhou, Chem. Soc. Rev., 2016, 45, $2327-2367$.

88 B. Wang, T. Rhauderwiek, A. K. Inge, H. Xu, T. Yang, Z. Huang, N. Stock and X. Zou, Chem. - Eur. J., 2018, 24, 17429-17433.

89 R. LaDuca, D. Rose, J. R. D. DeBord, R. C. Haushalter, C. J. O’Connor and J. Zubieta, J. Solid State Chem., 1996, 123, $408-412$.

90 A. Marques, M. Marin and M.-F. Ruasse, J. Org. Chem., 2001, 66, 7588-7595.

91 H. Liang, B. Zhou, D. Wu, J. Li and B. Li, Adv. Colloid Interface Sci., 2019, 272, 102019.

92 N. R. Perron and J. L. Brumaghim, Cell Biochem. Biophys., 2009, 53, 75-100.

93 Md. A. Rahim, S. L. Kristufek, S. Pan, J. J. Richardson and F. Caruso, Angew. Chem. Int. Ed., 2019, 58, $1904-1927$.

94 J. Yu, B. Cheng and H. Ejima, J. Mater. Chem. B, 2020, 8, 6798-6801.

95 J. M. Herrero-Martínez, M. Sanmartin, M. Rosés, E. Bosch and C. Ràfols, ELECTROPHORESIS, 2005, 26, 1886-1895.

96 A. Avdeef, S. R. Sofen, T. L. Bregante and K. N. Raymond, J. Am. Chem. Soc., 1978, 100, 5362-5370.

97 R. K. Feller and A. K. Cheetham, Solid State Sci., 2006, 8, 1121-1125.

98 P. J. Saines, H. H.-M. Yeung, J. R. Hester, A. R. Lennie and A. K. Cheetham, Dalton Trans., 2011, 40, 6401-6410.

99 G. Mouchaham, L. Cooper, N. Guillou, C. Martineau, E. Elkaim, S. Bourrelly, P. L. Llewellyn, C. Allain, G. Clavier, C. Serre and T. Devic, Angew. Chem.-Int. Ed., 2015, 54, 13297-13301.

100 M. Hmadeh, Z. Lu, Z. Liu, F. Gándara, H. Furukawa, S. Wan, V. Augustyn, R. Chang, L. Liao, F. Zhou, E. Perre, V. Ozolins, K. Suenaga, X. Duan, B. Dunn, Y. Yamamto, O. Terasaki and O. M. Yaghi, Chem. Mater., 2012, 24, 3511-3513.

101 G. V. Shilov, Z. K. Nikitina, N. S. Ovanesyan, S. M. Aldoshin and V. D. Makhaev, Russ. Chem. Bull., 2011, 60, 12091219.

102 H. Nagatomi, N. Yanai, T. Yamada, K. Shiraishi and N. Kimizuka, Chem. - Eur. J., 2018, 24, 1806-1810.

103 F. Wang, Z. Liu, C. Yang, H. Zhong, G. Nam, P. Zhang, R. Dong, Y. Wu, J. Cho, J. Zhang and X. Feng, Adv. Mater., 2020, 32, 1905361. 
104 H. Zhong, K. H. Ly, M. Wang, Y. Krupskaya, X. Han, J. Zhang, J. Zhang, V. Kataev, B. Büchner, I. M. Weidinger, S. Kaskel, P. Liu, M. Chen, R. Dong and X. Feng, Angew. Chem. Int. Ed., 2019, 58, 10677-10682.

105 Z. Meng, A. Aykanat and K. A. Mirica, J. Am. Chem. Soc., 2019, 141, 2046-2053.

106 H. Jia, Y. Yao, J. Zhao, Y. Gao, Z. Luo and P. Du, J. Mater. Chem. A, 2018, 6, 1188-1195.

107 S. Jin, J. P. Hill, Q. Ji, L. K. Shrestha and K. Ariga, J. Mater. Chem. A, 2016, 4, 5737-5744.

108 S. Jin, C. Li, L. K. Shrestha, Y. Yamauchi, K. Ariga and J. P. Hill, ACS Appl. Mater. Interfaces, 2017, 9, 18782-18789.

109 A. Wang, L. Cheng, X. Shen, W. Zhu and L. Li, Dyes Pigments, 2020, 181, 108568.

110 A. Wang, L. Cheng, X. Shen, X. Chen, W. Zhu, W. Zhao and C. Lv, Chem. Eng. J., 2020, 400, 125975.

111 G. Mouchaham, B. Abeykoon, M. Giménez-Marqués, S. Navalon, A. Santiago-Portillo, M. Affram, N. Guillou, C. Martineau, H. Garcia, A. Fateeva and T. Devic, Chem. Commun., 2017, 53, 7661-7664.

112 S. De, G. C. Quan, B. Gikonyo, C. Martineau-Corcos, C. Bousige, L. Veyre, T. Devic, C. Marichy and A. Fateeva, Inorg. Chem., 2020, 59, 10129-10137.

113 E.-X. Chen, M. Qiu, Y.-F. Zhang, Y.-S. Zhu, L.-Y. Liu, Y.-Y. Sun, X. Bu, J. Zhang and Q. Lin, Adv. Mater., 2018, 30, 1704388.

114 Y.-J. Guo, E.-X. Chen, E. Yang and Q. Lin, J. Solid State Chem., 2020, 285, 121224.

115 X. Feng, X. Wang, H. Wang, H. Wu, Z. Liu, W. Zhou, Q. Lin and J. Jiang, ACS Appl. Mater. Interfaces, 2019, 11, $45118-45125$.

116 J.-P. Zhang, Y.-B. Zhang, J.-B. Lin and X.-M. Chen, Chem. Rev., 2012, 112, 1001-1033.

117 Y.-L. Dong, L. Xu, X.-D. Yang, Z. Su and H.-K. Liu, Inorg. Chem. Commun., 2019, 104, 14-18.

118 J. F. Satchell and B. J. Smith, Phys. Chem. Chem. Phys., 2002, 4, 4314-4318.

119 G. E. Kostakis, G. Abbas, C. E. Anson and A. K. Powell, CrystEngComm, 2009, 11, 82-86.

120 M. Dincă, A. F. Yu and J. R. Long, J. Am. Chem. Soc., 2006, 128, 8904-8913.

121 M. Dincă, A. Dailly and J. R. Long, Chem. - Eur. J., 2008, 14, 10280-10285.

122 X.-S. Wang, Y.-Z. Tang, X.-F. Huang, Z.-R. Qu, C.-M. Che, P. W. H. Chan and R.-G. Xiong, Inorg. Chem., 2005, 44, 5278-5285.

123 Y. Chen, Z.-G. Ren, H.-X. Li, X.-Y. Tang, W.-H. Zhang, Y. Zhang and J.-P. Lang, J. Mol. Struct., 2008, 875, 339-345.

124 M. Dincă, A. Dailly, C. Tsay and J. R. Long, Inorg. Chem., 2008, 47, 11-13.

125 T. Wu, M. Chen and D. Li, Eur. J. Inorg. Chem., 2006, 2006, 2132-2135.

126 N. Masciocchi, M. Moret, P. Cairati, A. Sironi, G. A. Ardizzoia and G. La Monica, J. Am. Chem. Soc., 1994, 116, 7668-7676.

127 N. Masciocchi, G. A. Ardizzoia, A. Maspero, G. LaMonica and A. Sironi, Inorg. Chem., 1999, 38, 3657-3664.

128 N. Masciocchi, G. A. Ardizzoia, S. Brenna, G. LaMonica, A. Maspero, S. Galli and A. Sironi, Inorg. Chem., 2002, 41, 6080-6089.

129 A. Cingolani, S. Galli, N. Masciocchi, L. Pandolfo, C. Pettinari and A. Sironi, J. Am. Chem. Soc., 2005, 127, 6144-

6145.

130 L. Xie, S. Liu, C. Gao, R. Cao, J. Cao, C. Sun and Z. Su, Inorg. Chem., 2007, 46, 7782-7788.

131 S. Das, H. Kim and K. Kim, J. Am. Chem. Soc., 2009, 131, 3814-3815.

132 V. Colombo, S. Galli, H. J. Choi, G. D. Han, A. Maspero, G. Palmisano, N. Masciocchi and J. R. Long, Chem. Sci., 2011, 2, 1311-1319. 
137 D. Liu, T.-F. Liu, Y.-P. Chen, L. Zou, D. Feng, K. Wang, Q. Zhang, S. Yuan, C. Zhong and H.-C. Zhou, J. Am. Chem. Soc., 2015, 137, 7740-7746.

138 B. Abeykoon, J.-M. Grenèche, E. Jeanneau, D. Chernyshov, C. Goutaudier, A. Demessence, T. Devic and A. Fateeva, Dalton Trans., 2017, 46, 517-523.

139 Z. Wang, J.-H. Zhang, J.-J. Jiang, H.-P. Wang, Z.-W. Wei, X. Zhu, M. Pan and C.-Y. Su, J. Mater. Chem. A, 2018, 6, 17698-17705.

140 A. Tăbăcaru, C. Pettinari and S. Galli, Coord. Chem. Rev., 2018, 372, 1-30.

141 D. Liu, X. Wang, Y.-P. Chen, S. Yuan, C. Zhong and H.-C. Zhou, Sci. China Chem., 2016, 59, 975-979.

142 A. Fateeva, J. Clarisse, G. Pilet, J.-M. Grenèche, F. Nouar, B. K. Abeykoon, F. Guegan, C. Goutaudier, D. Luneau, J. E. Warren, M. J. Rosseinsky and T. Devic, Cryst. Growth Des., 2015, 15, 1819-1826.

143 K. Zhang, Z. Qiao and J. Jiang, Cryst. Growth Des., 2017, 17, 543-549.

144 K. Wang, X.-L. Lv, D. Feng, J. Li, S. Chen, J. Sun, L. Song, Y. Xie, J.-R. Li and H.-C. Zhou, J. Am. Chem. Soc., 2016, 138, 914-919.

145 X.-L. Lv, K. Wang, B. Wang, J. Su, X. Zou, Y. Xie, J.-R. Li and H.-C. Zhou, J. Am. Chem. Soc., 2017, 139, $211-217$.

146 N. Huang, K. Wang, H. Drake, P. Cai, J. Pang, J. Li, S. Che, L. Huang, Q. Wang and H.-C. Zhou, J. Am. Chem. Soc., $2018,140,6383-6390$.

147 W. Morris, B. Volosskiy, S. Demir, F. Gándara, P. L. McGrier, H. Furukawa, D. Cascio, J. F. Stoddart and O. M. Yaghi, Inorg. Chem., 2012, 51, 6443-6445.

148 T.-F. Liu, D. Feng, Y.-P. Chen, L. Zou, M. Bosch, S. Yuan, Z. Wei, S. Fordham, K. Wang and H.-C. Zhou, J. Am. Chem. Soc., $2015,137,413-419$.

149 D. Feng, Z.-Y. Gu, J.-R. Li, H.-L. Jiang, Z. Wei and H.-C. Zhou, Angew. Chem. Int. Ed., 2012, 51, 10307-10310.

150 H.-L. Jiang, D. Feng, K. Wang, Z.-Y. Gu, Z. Wei, Y.-P. Chen and H.-C. Zhou, J. Am. Chem. Soc., 2013, 135, 1393413938.

151 L. Xu, Y.-P. Luo, L. Sun, Y. Xu, Z.-S. Cai, M. Fang, R.-X. Yuan and H.-B. Du, Chem. - Eur. J., 2016, 22, 6268-6276.

152 P. Li, R. C. Klet, S.-Y. Moon, T. C. Wang, P. Deria, A. W. Peters, B. M. Klahr, H.-J. Park, S. S. Al-Juaid, J. T. Hupp and O. K. Farha, Chem. Commun., 2015, 51, 10925-10928.

153 J. Ma, L. D. Tran and A. J. Matzger, Cryst. Growth Des., 2016, 16, 4148-4153.

154 A. Schoedel, M. Li, D. Li, M. O’Keeffe and O. M. Yaghi, Chem. Rev., 2016, 116, 12466-12535.

155 T. Devic and C. Serre, Chem. Soc. Rev., 2014, 43, 6097-6115.

156 N. ul Qadir, S. A. M. Said and H. M. Bahaidarah, Microporous Mesoporous Mater., 2015, 201, 61-90.

157 T. Rhauderwiek, S. Waitschat, S. Wuttke, H. Reinsch, T. Bein and N. Stock, Inorg. Chem., 2016, 55, 5312-5319.

158 G. Liu, H. Cui, S. Wang, L. Zhang and C.-Y. Su, J. Mater. Chem. A, 2020, 8, 8376-8382. 